\title{
Modify the Re-Defined: Strategic Human Resource Development Maturity at a Crossroads
}

\begin{abstract}
This integrative literature review reports on strategic human resource development (SHRD) models that examine the strategic embeddedness of HRD (SHRD maturity) in organizations. A review and critique of all existing SHRD models is provided, exemplifying their limitations and building upon their strengths to inform a modified SHRD framework. The latter suggests an enhanced set of strategic components to assess SHRD maturity. This paper further outlines how SHRD aspirations can be practiced within complex, dynamic, and continually changing business and economic environments. The SHRD literature is advanced by new insights on how HRD scholars and practitioners could assess and enhance the maturity of their HRD interventions in the context of constantly changing (dynamic) environments. The modified SHRD framework further contributes to the academic literature with its enhanced set of strategic characteristics, as well as with its SHRD pointers, all of which can offer a better evaluation of SHRD maturity during periods of business and economic complexity and uncertainty.
\end{abstract}

Keywords: Strategic Human Resource Development, SHRD Maturity, Complex and Dynamic Environments, Integrative Literature Review 


\section{Introduction}

The mainstream literature highlights the strategic significance of human resource development (HRD) as a fundamental tool for enhancing workforce capabilities, knowledge, efficiency, and adaptability (Garavan et al., 2016; Alagaraja, 2013a, 2013b; Gibb, 2011; Garavan, 2007). However, many HRD professionals fail to demonstrate the value proposition of their department (O’Donovan \& Rimland-Flower, 2013). In addition, the unfavorable conditions brought about by the global financial crisis (early 2007 onwards) altered the practice of HRD in many organizations, by further challenging its value-added capacity as well as questioning its strategic focus (Sung and Choi, 2013; Wang et al., 2009).

In response to the above, several strategic human resource development (SHRD) models have been proposed to assess the strategic embeddedness of HRD in organizations (Garavan, 2007; Robinson \& Robinson, 2005; Boudreau \& Ramstad, 2004; Gilley \& Gilley, 2003; Becker et al., 2001; Gilley \& Maycunich, 2000a, 2000b; McCracken \& Wallace 2000a, 2000b; Ulrich, 1998; Pfeffer, 1998; Lee, 1996a, 1996b; Garavan, 1991). However, their major limitation relates to their application and operationalization within 'static' business and economic environments. Therefore, all of these models fail to reflect how organizations manage their HRD practices within complex, dynamic, and constantly changing business and economic contexts. Furthermore, following the evolving nature of the HRD concept, emerging research should reflect ongoing business and economic complexities to enable organizations to redesign and deliver their HRD interventions more strategically in order to gain sustainable competitive advantage. Thus, the author suggests a modified SHRD framework (figure 3).

The modified SHRD framework builds upon and enhances the most cited and most comprehensive SHRD model (that of McCracken \& Wallace, 2000a, 2000b). A new cluster of strategic criteria serves as a tool to assess SHRD maturity better, further complemented by specific pointers for each of the strategic components. The modified SHRD framework will 
help HRD scholars and practitioners in identifying the potential problems and limitations of putting SHRD aspirations into practice under periods of business and economic uncertainty and complexity. Furthermore, it could set the foundational points for future research on SHRD maturity by testing its applicability and operationalization both within the context of dynamic environments, as well as within different national, industrial, and environmental contexts.

\section{Methodology}

This integrative literature review offers a critical evaluation of the SHRD literature relating to SHRD models. The modified SHRD framework (and its enhanced set of strategic components) was highly informed by the strategic propositions offered by existing SHRD models to better assess SHRD maturity. Additionally, the author offers specific SHRD pointers to support each respective strategic criterion of the modified SHRD framework.

To serve the purpose of this integrative literature review, various research articles, books, dissertations, and conference papers that inform the academic knowledge of SHRD maturity were reviewed. Databases such as Google Scholar, Web of Science, JStor, EBSCO library, British Library EThOS, and Science Direct were accessed. To identify the most relevant articles, ABS-ranked journals were used, including Human Resource Development Review, HRD International, HRD Quarterly, Advances in Human Resource Development, Journal of European Industrial Training, European Journal of Training and Development, Advances in Developing Human Resources, and International Journal of Training and Development. Finally, several HRD books were also reviewed and found to offer relevant points. The literature review was limited only to those sources featuring one or more of the chosen keywords within their abstract, main body, or title, as well as being published in English in various academic journals or included in books.

The inclusion criteria for the articles, books, dissertations, and conference papers for review, 
from those databases that were assessed, comprised key search terms such as 'strategic human resource development, ' SHRD models', 'SHRD maturity', 'strategic embeddedness of HRD', 'strategic characteristics of HRD', and 'Strategic Business Partner'. Garavan (1991) developed the first SHRD model, so the inclusion criteria were also informed by the year of publication, as well as the country where the research was conducted. Thus, a data search timeframe was set (January 1990 to September 2018) to allow consideration of all work published within this period. The search returned many articles and books, the vast majority of which were published in the US and the UK (with a few in other countries, e.g., Ireland, Greece). Approximately a hundred (100) outputs were reviewed in total. However, only twenty (20) of these were used (Appendix 1). Precisely, ten (10) journal articles were identified, along with eight (8) books, one (1) conference paper, and one (1) Ph.D. thesis, all of which directly referred to the key search terms mentioned above. All other search results, without a primary focus on the key search terms, were excluded; thus, leading to the exclusion of 80 records. However, some of these were considered later to support part of the strategic propositions of the existing SHRD models or of those that were offered by the modified SHRD framework.

All relevant points were grouped into specific key themes in line with the strategic components of the existing SHRD models, and with those that were proposed by the modified SHRD framework. Indirect points were also arranged according to their degree of relevance to those strategic characteristics. Overall, all points outlined the complexity that could be attached to the notion of SHRD maturity, especially in the context of dynamic environments. A thoughtful review of all relevant material allowed the author to develop a modified SHRD framework.

The following section (divided into sub-sections) will offer a review and critique of all existing SHRD models by highlighting their strengths and weaknesses, and exemplifying how these have informed the modified SHRD framework. 


\section{Existing SHRD maturity models: review and critique}

The extant literature offers many SHRD models (table 1), all of which propose a set of characteristics to assess the strategic embeddedness of HRD in organizations. All SHRD models (14 in total; table 1 , and figures $1 \& 2$ ) outline the way in which HRD could enhance its strategic focus using the available evidence with respect to their strategic criteria (Garavan, 2007; Robinson \& Robinson, 2005; Boudreau \& Ramstad, 2004; Gilley \& Gilley, 2003; Becker et al., 2001; Gilley \& Maycunich, 2000a, 2000b; McCracken \& Wallace 2000a, 2000b; Ulrich, 1998; Pfeffer, 1998; Lee, 1996a, 1996b; Garavan, 1991). A review of their respective SHRD propositions is offered in the following sub-sections, along with identifying their strong and weak points, all of which informed the modified SHRD framework.

\begin{tabular}{|c|c|c|c|}
\hline Garavan (1991) & $\begin{array}{c}\text { Torraco \& Swanson } \\
\text { (1995) }\end{array}$ & Lee (1996) & Pfeffer (1998) \\
\hline $\begin{array}{l}\text { Integration with organizational } \\
\text { missions and goals }\end{array}$ & $\begin{array}{l}\text { Shape business } \\
\text { strategy by }\end{array}$ & Scale of Training Maturity & $\begin{array}{c}\text { Create Chief People } \\
\text { Officers by }\end{array}$ \\
\hline Top management support & Being performance based & $\begin{array}{l}\text { 1) Training and learning are } \\
\text { processes through which strategy is } \\
\text { formulated }\end{array}$ & $\begin{array}{l}\text { Building trust through } \\
\text { sharing information and } \\
\text { power }\end{array}$ \\
\hline HRD plans and policies & $\begin{array}{l}\text { Demonstrating strategic } \\
\text { capability }\end{array}$ & $\begin{array}{l}\text { 2) Training and learning possibilities } \\
\text { help to shape strategy }\end{array}$ & Encouraging change \\
\hline Environmental scanning & $\begin{array}{l}\text { Utilizing employee } \\
\text { expertise }\end{array}$ & $\begin{array}{l}\text { 3) Training is the means for } \\
\text { implementing corporate strategy } \\
\text { and achieving change }\end{array}$ & $\begin{array}{l}\text { Measuring key drivers of } \\
\text { success }\end{array}$ \\
\hline $\begin{array}{l}\text { Line Managers commitment \& } \\
\text { involvement }\end{array}$ & & $\begin{array}{l}\text { 4) Training integrated with } \\
\text { operational management }\end{array}$ & \\
\hline Complementary HRM activities & & 5) Isolated tactical training & \\
\hline Recognition of culture & & 6) No systematic training & \\
\hline Emphasis on evaluation & & & \\
\hline
\end{tabular}

Table 1: Existing SHRD models. 


\begin{tabular}{|c|c|c|c|}
\hline Ulrich (1998) & $\begin{array}{l}\text { McCracken \& Wallace } \\
(2000 \mathrm{a}, 2000 \mathrm{~b})\end{array}$ & Dwyer (2000) & $\begin{array}{c}\text { Gilley \& Maycunich } \\
(2000 \mathrm{a}, 2000 \mathrm{~b})\end{array}$ \\
\hline $\begin{array}{l}\text { Partner with senior and line } \\
\text { management }\end{array}$ & $\begin{array}{l}\text { Shaping organizational missions } \\
\text { and goals }\end{array}$ & $\begin{array}{l}\text { Measure performance in } \\
\text { quantifiable terms \& } \\
\text { communicate impact of } \\
\text { long-term human capital } \\
\text { investments }\end{array}$ & $\begin{array}{l}\text { Focus on: } \\
\text { Organizational Learning } \\
\text { Organizational } \\
\text { Performance } \\
\text { Organizational change }\end{array}$ \\
\hline $\begin{array}{l}\text { Be experts in how work is } \\
\text { organised and executed }\end{array}$ & Top management leadership & $\begin{array}{l}\text { Know micro \& } \\
\text { macroeconomic political } \\
\text { \& social realities }\end{array}$ & $\begin{array}{l}\text { Domains } \\
\text { Analysis } \\
\text { Design of initiatives \& } \\
\text { interventions } \\
\text { Evaluation }\end{array}$ \\
\hline Be a champion for employees & $\begin{array}{l}\text { Environmental scanning by } \\
\text { senior management, in HRD } \\
\text { terms }\end{array}$ & $\begin{array}{l}\text { Investigate business } \\
\text { needs \& drive action } \\
\text { essential to business } \\
\text { suocess }\end{array}$ & $\begin{array}{l}\text { Elements } \\
\text { HRD transfomation } \\
\text { HRD leadership } \\
\text { Principles of strategic } \\
\text { HRD } \\
\end{array}$ \\
\hline \multirow[t]{6}{*}{$\begin{array}{l}\text { Be a champion for oontinual } \\
\text { organizational transformation }\end{array}$} & HRD strategies, policies \& plans & & \\
\hline & $\begin{array}{l}\text { Strategic partnerships with line } \\
\text { management }\end{array}$ & & \\
\hline & Strategio partnerships with HRM & & \\
\hline & $\begin{array}{l}\text { Trainers as organizational } \\
\text { change consultants }\end{array}$ & & \\
\hline & Ability to influence corp. culture & & \\
\hline & $\begin{array}{l}\text { Emphasis on cost-effectiveness } \\
\text { evaluation }\end{array}$ & & \\
\hline $\begin{array}{l}\text { Becker, Huselid \& Ulrich } \\
\text { (2001) }\end{array}$ & Gilley \& Gilley (2003) & $\begin{array}{c}\text { Boudreau \& } \\
\text { Ramstad (2004) }\end{array}$ & $\begin{array}{c}\text { Robinson \& } \\
\text { Robinson }(2005)\end{array}$ \\
\hline \multirow[t]{3}{*}{$\begin{array}{l}\text { Develop rigorous } \\
\text { measurement systems }\end{array}$} & $\begin{array}{l}\text { Domains } \\
\text { Organizational Learning } \\
\text { Organizational performance } \\
\text { Organizational change }\end{array}$ & $\begin{array}{l}\text { Human Capacity } \\
\text { Bridge Framework }\end{array}$ & $\begin{array}{l}\text { Build client } \\
\text { partnership } \\
\text { Acoess } \\
\text { Credibility } \\
\text { Trust }\end{array}$ \\
\hline & $\begin{array}{l}\text { Steps } \\
\text { Communicate urgency for } \\
\text { change } \\
\text { Provide leadership } \\
\text { Create ownership } \\
\text { Implement } \\
\text { Integrate change into org. culture } \\
\text { Measure progress }\end{array}$ & $\begin{array}{l}\text { Anchor Points } \\
\text { Impact } \\
\text { Effectiveness } \\
\text { Efficiency }\end{array}$ & $\begin{array}{l}\text { Identify \& partner to } \\
\text { support projects } \\
\text { Reframe requests } \\
\text { Proactively identify } \\
\text { strategic opportunities } \\
\text { Implement projects }\end{array}$ \\
\hline & $\begin{array}{l}\text { Result } \\
\text { Successtul transformation of } \\
\text { HRD }\end{array}$ & $\begin{array}{l}\text { Linking Elements } \\
\text { Sustainable strategic } \\
\text { suocess, Resources \& } \\
\text { process, Talent pools } \\
\text { Aligned actions } \\
\text { Human capacity } \\
\text { Policies \& practices } \\
\text { Investments }\end{array}$ & $\begin{array}{l}\text { Influence business } \\
\text { strategies and } \\
\text { direction } \\
\text { Contribute to formation } \\
\text { of plans } \\
\text { Integrate HR strategic } \\
\text { plan into business plan } \\
\text { Implement people } \\
\text { initiatives }\end{array}$ \\
\hline
\end{tabular}

Table 1: Existing SHRD models (continued). 


\section{SHRD Propositions - Garavan (1991)}

Garavan (1991) was amongst the first to develop an SHRD model (table 1), which consisted nine key strategic criteria describing SHRD maturity. The author further argued that HRD should be either vertically or horizontally integrated with corporate objectives. This is indeed a vital suggestion that could offer an indication of an HRD strategic approach through matching its objectives with the organization's objectives (horizontal), as well as with those of HRM (vertical). However, rather than focusing solely either on vertical or horizontal integration, external and internal integration should also be considered in order to place HRD at the axis of an organization's life. Thus, multi-dimensional integration should be suggested instead.

The modified SHRD framework developed in this work embraces Garavan's (1991) suggestion by welcoming both vertical (HRD with HRM) and horizontal (HRD with corporate objectives/strategy) integration. To support these further, both internal (e.g., HRD with other business operations) and external integration (through 'environmentally integrated' HRD strategies, plans, and policies, as suggested by the modified SHRD framework) are suggested, which could enable HRD professionals to ensure constant evaluation of the existent uncertainties and complexities within both the micro- and macro-environmental contexts. Therefore, the multi-dimensional integration that the modified SHRD framework suggests can enhance the strategic outlook of HRD, and the value proposition of its professionals, by allowing them to better reflect the complex and dynamic nature of the contemporary business world.

Finally, after Garavan's (1991) model was tested within specific national and industrial contexts, the author offered a universalistic perspective of HRD by implying that his suggestions could apply in other similar contexts. However, practical difficulties could emerge by generalizing ethnocentric approaches, such as the best way to conduct research and report findings (Cooke, 2018). 


\section{SHRD Propositions - Torraco and Swanson (1995)}

Following the development of the SHRD literature, Torraco and Swanson (1995) suggested three distinctive criteria that could enhance the strategic outlook of HRD (table 1). Thus, the authors argued that in order to talk about SHRD, this should be able to shape business strategy by being performance oriented; by utilizing employee expertise; and by demonstrating strategic capabilities. Indeed, these propositions are meaningful and profoundly informed the modified SHRD framework proposed in this work.

For instance, the proposition of utilizing employee expertise is embraced by two strategic components of the modified SHRD framework, namely the "environmental scanning, in HRD terms, by including senior managers, line managers (LMs) and employees", and the "strategic partnerships with key organizational stakeholders (LMs, top management, employees)". Both criteria suggest that employees' input could prove valuable as they could offer valuable insights into all aspects of the business. Additionally, the strategic capabilities are closely related to the proposition of viewing HRD as a strategic business partner in organizations. However, instead of having HRD performance oriented, it would be better to focus on it attaining a strategic business partnering role in organizations, through which performative outcomes could also emerge, which is a key suggestion offered by the modified SHRD framework.

\section{SHRD Propositions - Lee (1996a, 1996b)}

A significant contribution to the SHRD knowledge was made by Lee (1996a, 1996b), who suggested a SHRD maturity scale (six layers) based on an organization's training and development (T\&D) approach. The author ranked T\&D according to its strategic integration with corporate strategy; thus, moving from the bottom level to the upper levels, organizations become more mature in HRD terms (figure 1). 


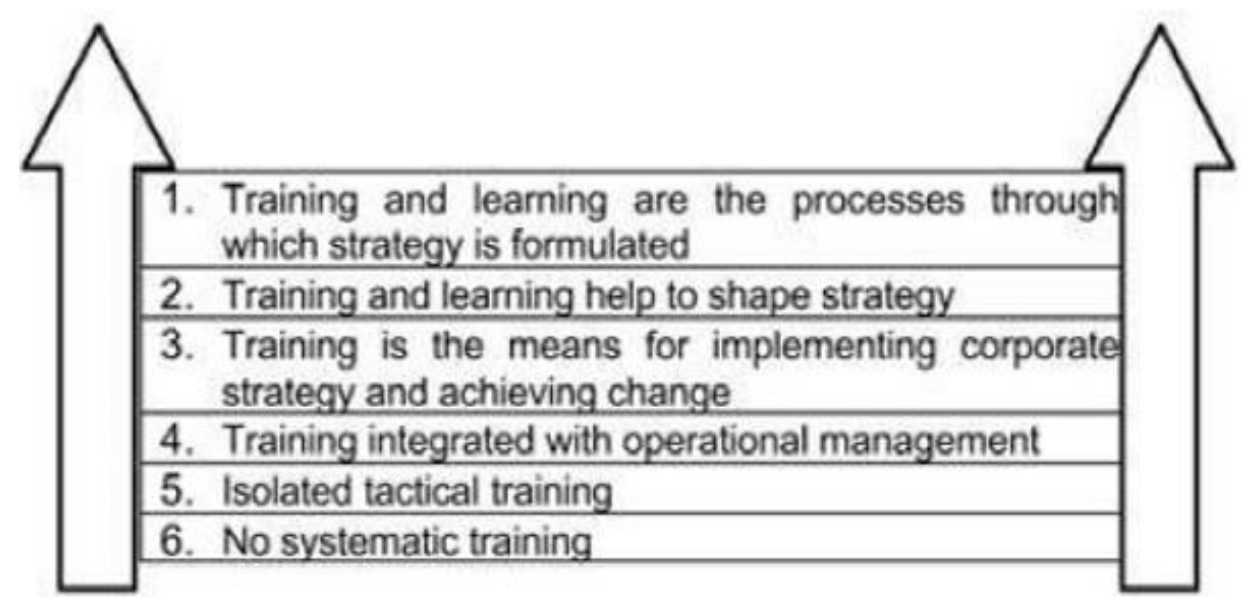

Figure 1: Scale of training maturity (Adapted from Lee, 1996b)

However, the author's sole focus on the sophistication of training ("the degree of their strategic integration with the corporate strategy") received extensive criticism as the volume of training itself cannot provide much evidence for classifying an organization as either SHRD mature or immature. The scale further neglects other important HRD practices (e.g., change management, appraisals, evaluation, career planning) that could enhance HRD's strategic outlook (Pfeffer, 1998; Ulrich, 1998). Moreover, it is not clear how the intensity of training could support, explain, and associate with all the strategic criteria of those SHRD models that utilized this scale. Therefore, new pointers of SHRD maturity are suggested to complement and support the enhanced set of strategic components that were introduced by the modified SHRD framework developed in this work (table 2).

\section{SHRD Propositions - Pfeffer (1998)}

The SHRD literature was further enhanced by the contributions made by Pfeffer (1998) who argued that it is through the provision of greater HRD interventions that its effectiveness and contribution can be maximized (table 1). However, the author's model does not outline the ways through which the maturity of HRD could be strengthened. The suggestion of 
"encouraging change" could also prove to be quite problematic since not all change is necessarily strategic.

Additionally, as with Garavan's (1991) and Torraco and Swanson's (1995) propositions, Pfeffer (1998) implied a short-term, financial-driven, and responsive HRD evaluation process. In contrast, the modified SHRD framework proposed in this work argues for a strategicoriented HRD evaluation process to be present through which both short- and long-term outcomes (e.g., learning transfer, societal outcomes, and return on investment) could emerge. Finally, all three models fail to explain the extent to which their strategic characteristics are equally weighted while assessing SHRD maturity, a proposition that is welcomed by the modified SHRD framework in an attempt to better assess SHRD maturity.

\section{SHRD Propositions - Ulrich (1998)}

Ulrich (1998) further argued that it is essential to consider the role of HRD professionals by describing them as 'chief people officers' (table 1). The author suggested that their role could be upgraded through sharing information and power with other organizational members, which in return could result in building trust amongst them. Indeed, this suggestion reflects the 'strategic partnership with key organizational stakeholders' proposition that is offered by the modified SHRD framework.

The "encouraging change" proposition is also meaningful, yet, as previously argued, not all change is necessarily strategic to inform the strategic outlook of HRD in organizations. Finally, the "measuring key drivers of success" proposition relates to the "emphasis on strategic HRD evaluation process' strategic component of the modified SHRD framework. Once more, it is evident that the existing SHRD models can inform the modified SHRD framework through their respective propositions. 


\section{SHRD Propositions - McCracken and Wallace (2000a, 2000b)}

McCracken and Wallace's (2000a, 2000b) SHRD model (table 1) aimed at advancing the SHRD maturity notion by initially re-defining the term as "strong evidence of the proposed SHRD characteristics" (p. 435). They further argued that all criteria should be strategically integrated and interrelated to promote the creation of a strong learning culture in organizations. The authors positioned HRD as the axis of an organization's life by suggesting the use of both vertical and horizontal integration. However, the "HRD as the axis of an organization's life" proposition could be strengthened through a multi-dimensional integration (e.g., vertical, horizontal, internal, and external), as suggested by the modified SHRD framework. Especially concerning internal and external integration, it could enable organizations (and their HRD professionals) to constantly evaluate both micro- and macro-environmental contexts, both of which could simultaneously hinder or expedite SHRD maturity in organizations.

A limitation of this SHRD model also relates to its emphasis on a cost-effective HRD evaluation process, thus focusing on short-term financial business results and cost control. Instead, the modified SHRD framework argues that long-term strategic outcomes, such as individual and organizational change, transfer of training/learning to job contexts, and societal outcomes, could also be attained without being to the detriment of short-term results. Following such an approach, along with all the other presented criteria, HRD could attain an equal strategic business-partnering role in the organization, a proposition made by Robinson and Robinson (2005) and embraced by the modified SHRD framework.

Overall, McCracken and Wallace's (2000a, 2000b) SHRD model offers many interesting points (e.g., HRD's ability to shape organizational missions and goals, strategic partnership with HRM, and active involvement of line managers), all of which have highly informed the respective criteria of the modified SHRD framework. Furthermore, McCracken and Wallace's (2000a, 2000b) model is the most cited and most comprehensive model within the SHRD 
literature, and that was why the author of the current paper decided to build upon and enhance their work through the modified SHRD framework.

\section{SHRD Propositions - Dwyer (2000)}

The propositions offered by Dwyer (2000, table 1) further informed the enhanced set of strategic components in the modified SHRD framework, but Dwyer's (2000) propositions also received criticism. For instance, the author's suggestion of "knowing the micro and macroeconomic political and social realities" as a key element to enhance the strategic outlook of HRD is closely associated with the 'environmentally integrated HRD strategies, plans, and policies' strategic component of the modified SHRD framework. In addition, the 'environmental scanning' and the 'strategic HRD evaluation' criteria of the modified SHRD framework could address the author's proposition of "investigating business needs and drive actions for business success".

However, in contrast to Dwyer's (2000) proposition of achieving performative outcomes, either through a contingency (e.g. HRD to align with business strategy) or through a configurational perspective (e.g. HRD to align with HRM), the modified SHRD framework argues that a multi-dimensional integration could place HRD at the axis of an organization's life, and thus to offer a better evaluation of the ongoing business and economic uncertainties.

\section{SHRD Propositions - Gilley and Maycunich (2000a, 2000b)}

Following the SHRD maturity discourse, Gilley and Maycunich (2000a) suggested that organizational performance, learning, and change could feature as critical components of SHRD maturity (table 1). The authors proposed a three-step process (analysis, the design of interventions, and evaluation) for measuring their effectiveness. However, these can be viewed as just common HRD practices, without truly enhancing SHRD maturity. The authors further 
added three more elements (HRD transformation, leadership, and principles of SHRD) influencing those practices. However, they did not explain how to test the extent to which these elements, domains, and practices can help HRD in becoming strategic. Therefore, their model could be unpractical by not detailing how it could be operationalized. In addition, Gilley and Maycunich's (2000a, 2000b) proposition of 'driving change' as an indication of the strategic outlook of HRD could be debated following an earlier suggestion that not all change is necessarily strategic.

A few interesting suggestions offered by this particular SHRD model, either directly or indirectly informed some of the respective strategic components of the modified SHRD framework. For instance, HRD leadership was considered through suggesting an 'extensive role of HRD executives', while the proposition of analyzing and designing proactive HRD interventions was welcomed within the 'environmentally integrated HRD strategies, plans and policies' suggestion of the modified SHRD framework.

\section{SHRD Propositions - Becker, Huselid, and Ulrich (2001)}

Later, Becker et al. (2001) argued that for HRD to become strategic, it should "develop rigorous measurement systems" (table 1). Their proposition is meaningful and to some extent is incorporated by the 'strategic HRD evaluation process' of the modified SHRD framework. However, the authors' end-point assumption (performative focus) restricts the 'strategic business partnering role' proposition of the modified SHRD framework, which suggests that through attaining a strategic business partner role in organizations, performative outcomes could also be achieved.

Further to the above, this particular SHRD model/framework lacks consideration of all other factors and elements (as noted earlier) that could simultaneously influence the strategic outlook and maturity of HRD in organizations. 


\section{SHRD Propositions - Gilley and Gilley (2003)}

Gilley and Gilley (2003) refined SHRD maturity by suggesting a seven-step process through which organizations can enhance the strategic outlook of their HRD interventions (table 1). Although their model refers to specific HRD behaviors (shared vision, ownership, change management, leadership), which could be turned into particular objectives, their propositions do not indicate how these elements interrelate to exemplify how these behaviors are strategic rather than being merely reactive. Furthermore, the model emphasizes 'driving change' (not all change is strategic) whilst totally neglecting how HRD could attain an influential and proactive role in organizations through a strategic business partnering role.

\section{SHRD Propositions - Boudreau and Ramstad (2004)}

Boudreau and Ramstad (2004) also developed a framework (table 1), named the Human Capacity Bridge Framework, by suggesting a connection between its anchor points and linking elements. They argued that organizational success could only be achieved by identifying those areas in which talent management could have the most significant impact. However, although talent management could feature as a strategic element of HRD, it cannot constitute a sole strategic indicator of SHRD maturity. Thus, this framework could be described as being an incomplete tool for assessing SHRD maturity.

\section{SHRD Propositions - Robinson and Robinson (2005)}

Robinson and Robinson (2005) argued that HRD needs to reposition itself as a strategic business partner in organizations by performing three HRD accountabilities (table 1). The authors argued that if HRD could influence business strategies and direction by identifying and collaborating with both to support business projects, as well as through building client partnerships, then it can enhance its strategic outlook. The authors' suggestion of HRD 
becoming an equal strategic business partner in the organization was highly welcomed by the modified SHRD framework, along with the respective HRD accountabilities, by having those rephrased as 'shaping organizational missions, goals, and strategies', and 'strategic partnerships with key stakeholders', two key strategic propositions of the modified SHRD framework.

\section{SHRD Propositions - Garavan (2007)}

Lastly, Garavan (2007) proposed an SHRD model with a primary focus on achieving performative outcomes (figure 2). In brief, the model suggests an interrelation between its elements, namely the global environment (local, national, and multinational conditions), the profile of the HRD professionals, the organizational context, the organizational stakeholders, and the HRD focus, orientation, and strategies in place. Garavan (2007) argued that the interplay of all these elements could inform the strategic embeddedness of HRD in organizations. 


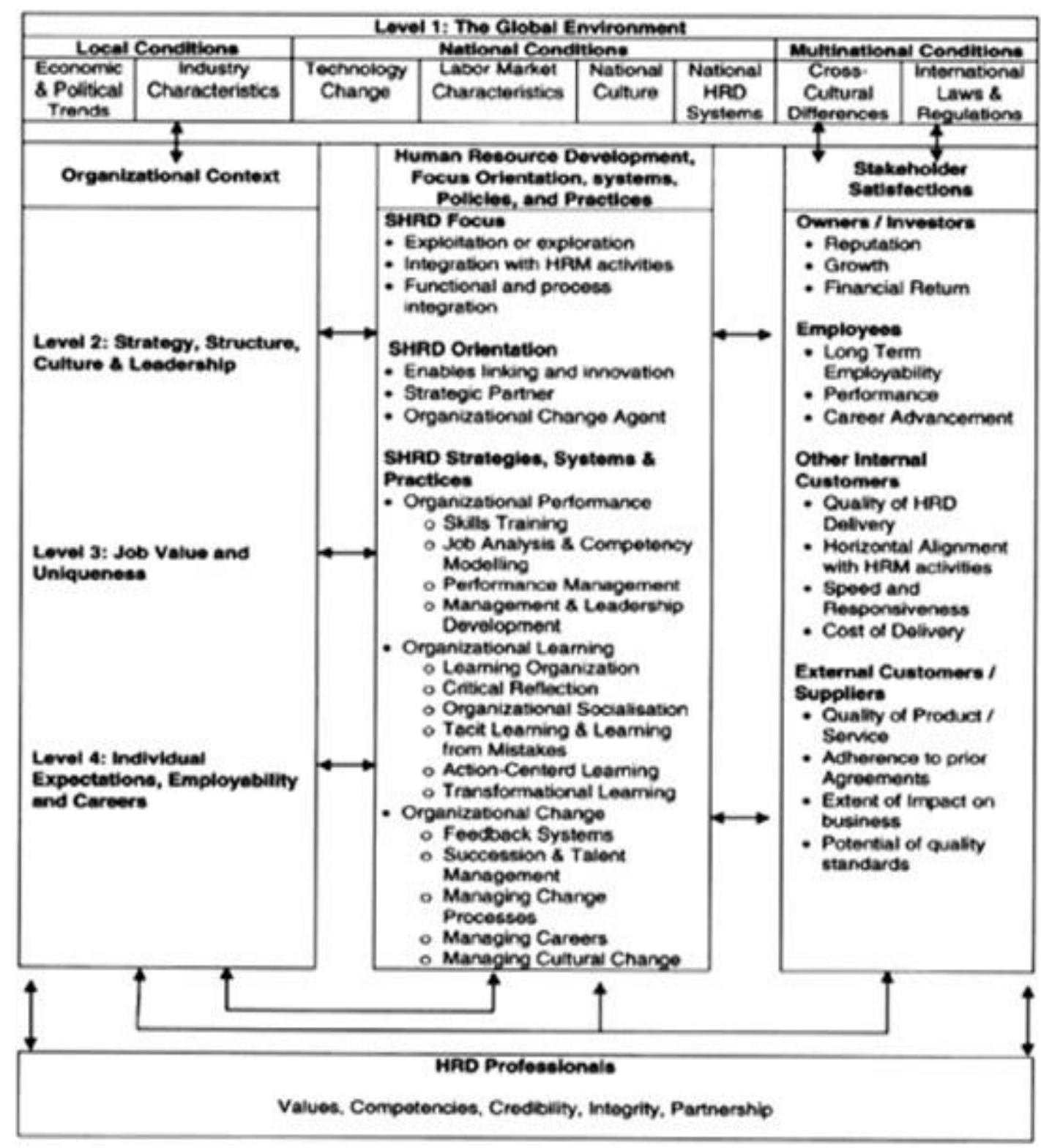

Figure 2: Garavan's (2007) SHRD model

The model is almost faultless, yet its complex nature hinders the understanding of SHRD. Its extensive external and internal dimensions (24 in total) and their expected outcomes (14) make the model difficult to operationalize, especially considering the complex and dynamic nature of contemporary business.

This model is amongst the two that account employees voice as a prerequisite element of the strategic maturity of HRD in organizations. The modified SHRD framework welcomes such a fundamental proposition through two strategic criteria, namely the 'environmental 
scanning, in HRD terms, through the inclusion of senior managers, line managers and employees', and the 'strategic partnerships with key organizational stakeholders'.

\section{Existing SHRD maturity models: concluding remarks}

Having reviewed existing SHRD models and outlined their strengths and weaknesses, it is easy to conclude that there are many suggestions as to how the strategic embeddedness of HRD could be enhanced. The 'ups and downs' of those SHRD models outline the complex nature surrounding the strategic embeddedness of HRD (SHRD maturity) in organizations. Such complexity could relate both with the application of those models in 'static' business environments, and results from the examination of the HRD concept from many different angles and contexts. Both result in identifying a contested territory concerning the understanding, application, and operationalization of SHRD amongst diverse organizations across the globe (Mitsakis, 2017; Mitsakis \& Aravopoulou, 2016).

Evidently, the notion of SHRD maturity is at a crossroads. Thus, a modified SHRD framework with an enhanced set of strategic components is proposed. Specific pointers of SHRD maturity (table 2) complement this new cluster of strategic criteria to enable HRD scholars and practitioners to operationalize and test the framework within challenging contexts, such as the global economic crisis or Brexit to better assess SHRD maturity. The modified SHRD framework further argues for the consideration of all of the micro- and macro-contextual factors that could simultaneously be at play and affect SHRD maturity. This suggestion could be addressed by the 'environmentally integrated HRD strategies, plans, and policies' proposition, a suggestion that is missing from most existing SHRD models. Therefore, future research would benefit from applying and testing the modified SHRD framework in different national, industrial, and environmental to make new suggestions. With all that said, the 
following section will discuss the enhanced set of strategic criteria offered by the modified SHRD framework.

\section{SHRD maturity at a crossroads: towards a modified cluster of strategic}

\section{components}

The modified SHRD framework (figure 3) builds upon and enhances the work of the most cited and most comprehensive SHRD model within the literature, that of McCracken and Wallace (2000a, 2000b). The modified SHRD framework proposes an enhanced set of eight strategic characteristics as components of SHRD maturity. The following paragraphs will describe all of the new propositions made by the modified SHRD framework in brief, before moving on to discuss each one in more detail in respective sub-sections.

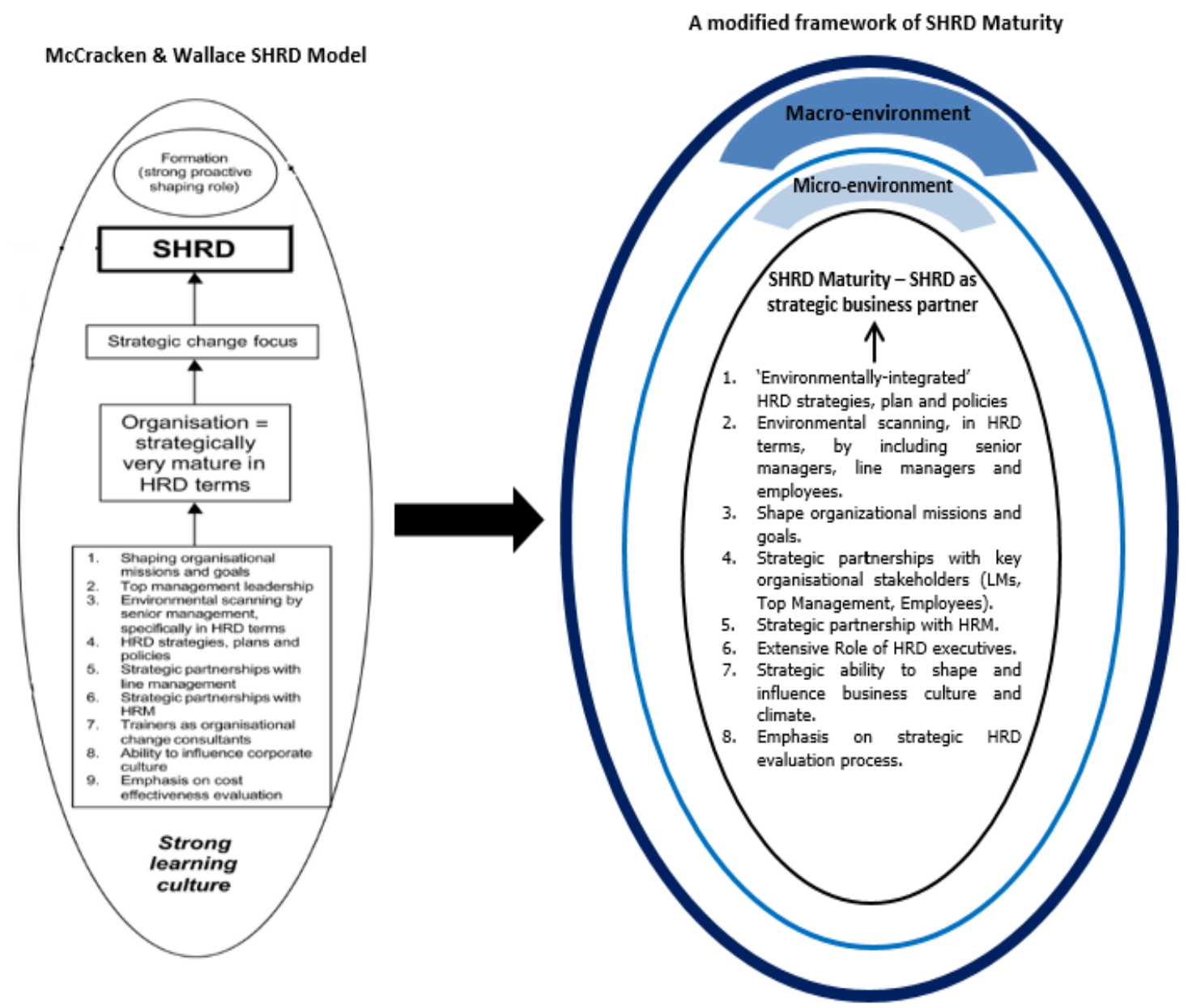

Figure 3: A modified framework to assess SHRD maturity. 
As a distinctive strategic criterion, the modified SHRD framework suggests that 'environmentally integrated' HRD strategies, plans, and policies should be in place to allow consideration of various micro- and macro-contextual factors (internal and external environments) that can simultaneously constrain or facilitate SHRD maturity in organizations. Therefore, it moves beyond a narrow focus on establishing either vertical or horizontal integration by suggesting that multi-dimensional integration could be attained instead, which could offer a better evaluation of the continually changing business and economic environments.

Furthermore, it embraces employees' voices within some of its strategic components to address a relevant gap that featured in most existing SHRD models. Therefore, rather than environmental scanning being conducting by senior managers only (Garavan, 1991; McCracken \& Wallace, 2000a, 2000b), the inclusion of line managers and employees is suggested instead as both stakeholder groups could offer insightful suggestions about this particular process. In line with this suggestion, the formation of strategic partnerships with key organizational stakeholders (top management, line managers, and employees) is also offered by the modified SHRD framework, rather than solely forming these with line managers (Garavan, 1991; McCracken \& Wallace, 2000a, 2000b). The modified SHRD framework suggests that all stakeholders should have a voice, and that could only happen by considering them as equal business partners, thus forming strategic partnerships with them.

A mature organization, in HRD terms, will also move beyond merely having clear HRD strategies, plans, and policies that align with corporate objectives (Garavan, 1991; McCracken \& Wallace, 2000a, 2000b). Instead, it will feature 'environmentally integrated HRD strategies, plans, and policies' through multidimensional integration (e.g., vertical, horizontal, internal, external) to make HRD the axis of the organizational life.

Furthermore, instead of focusing on performative outcomes through a cost-effective 
evaluation of the HRD practices, the modified SHRD framework argues that the maturity of HRD could be strengthened through a strategic-oriented evaluation within which strategic outcomes, of both performative and humanitarian nature, are also expected to emerge. By placing a strategic focus on all of its aspects, HRD could enhance its strategic position within the business and eventually be regarded as an equal strategic business partner.

Finally, in order to address the limitation that accompanies the 'scale of maturity' (volume/intensity of training) proposition made by Lee (1996b), and to enhance the SHRD maturity definition provided by McCracken and Wallace (2000a, 2000b), the term is re-defined as "the presence of strong or weak evidence of the suggested strategic criteria, and of their respective pointers".

Having considered the new suggestions of the modified SHRD framework, in brief, the following sub-sections will discuss all strategic characteristics in more detail to highlight how these could inform the HRD literature and practice.

\section{'Environmentally integrated' HRD strategies, plans, and policies.}

Various micro- and macro-environmental forces can create turbulence in the business world faster than organizations can become strategically oriented (Fiksel, 2015; Bardoel et al., 2014; O'Donovan \& Rimland-Flower, 2013). With that in mind, strategically focused organizations are expected to perform at higher levels even when environmental pressures escalate, threats ascend, and uncertainty intensifies (Boin \& Van Eaten, 2013). However, such an organizational capacity could be controversial to the extent that this is the outcome of a strategically designed business process or just the result of improvisation/pure luck (ibid). A recent survey conducted by Garavan et al. (2016) argued that the biggest challenge for SHRD is to offer those interventions that will result in the creation of new dynamic capabilities or the enhancement of existing ones and will eventually help organizations respond to environmental changes 
effectively. In line with this suggestion, the 'environmentally integrated' HRD strategies, plans, and policies proposition of the modified SHRD framework could lead to the desired outcomes suggested above.

Featuring 'environmentally integrated' HRD strategies, plans, and policies can allow organizations to establish a better fit with their internal and external environments, to reduce operational risk through increasing their sensitivity against on-going change, and to enhance their operational excellence and competitive advantage (Chen et al., 2015; Paille et al., 2014; Torugsa et al., 2013; Vogel \& Guttel, 2013; Vidal-Salazar et al., 2012). Many organizations fail to respond and adjust to fast-changing business and economic environments, resulting in lower competitiveness and reduced support from their stakeholders (Ulrich \& Dulebohn, 2015; Marchington, 2015; Gunnigle et al., 2013). Therefore, organizations need to adopt longterm/proactive HRD strategies to address future challenges successfully, which can only happen if a strategic/multidimensional integration is in place through 'environmentally integrated' HRD strategies, plans, and policies. In addition, proactive HRD investments could enhance individuals' capabilities and performance, as well as the organizational competitive advantage, through the creation of a supportive learning environment (Bardoel et al., 2014; Jiang et al., 2012; Felstead et al., 2012a; 2012b; Sthapit, 2010; Avey et al., 2011; Avey et al., 2010).

Overall, the modified SHRD framework suggests the adoption of 'environmentally integrated' HRD strategies, plans, and policies under both an exploitation (short-term) and exploration (long-term) orientation. The framework further suggests that multi-dimensional integration could also strengthen the resilience and sustainability of HRD. It could also allow organizations to maintain a regular fit with the latest developments occurring within both environmental contexts. Although some may argue that such an ability is part of an organization's reactive response (thus, there is no real need for specific strategic components), 
the modified SHRD framework argues that there is a strong interrelation between the strategic characteristics without amplifying one at the exclusion of the other (even if the emphasis placed on each one may vary over time).

Since research is nascent in testing SHRD models within dynamic environmental contexts, this specific strategic component of HRD could prove valuable to HRD executives in enhancing their strategies, plans, and policies. It could also allow organizations to change at relatively short notice and at a low cost, whilst also developing and applying dynamic strategic moves in response to emerging opportunities and developing trends (Jamrog et al., 2006). Having that element secured, coupled with evidence for the rest of the strategic criteria proposed, SHRD will move closer to a mature state and eventually is expected to attain a strategic business-partnering role. Thus, 'environmental scanning, in HRD terms, through the inclusion of senior managers, line managers, and employees' is also essential for enhancing the strategic embeddedness of HRD in organizations.

\section{Environmental scanning, in HRD terms, through the inclusion of senior managers, line managers (LMs), and employees}

The interplay of several factors (i.e., socio-cultural, technological, environmental, economic, political, legal) can, either directly or indirectly, influence organizational processes and SHRD maturity. Grant (2015) argued that organizational capacity (including HRD capacity) to address the impact of those factors could be a predictor of business success.

Therefore, environmental scanning of both the internal and external environments is essential. Organizations should always identify their strengths and weaknesses by assessing the former, as well as addressing opportunities and threats from the latter (Coombs, 2014). Having acknowledged that environmental scanning is essential, most SHRD models suggest that only senior managers should conduct relevant activities, with some others neglecting this 
proposition. However, insightful suggestions could also come from other key organizational stakeholders (e.g., line managers, employees), a proposition made by the respective strategic criterion of the modified SHRD framework.

According to David (2016), the most critical factor for expanding organizational attention to HRD is its reaction to environmental challenges. The author further argues that staying upto-date with ongoing change could enable HRD professionals to re-organize their objectives more easily to meet new environmental requirements (ibid). Moreover, Buller and McEvoy (2012) argued that relevant processes allow organizations to match environmental challenges with their human capital capabilities to achieve a competitive advantage. Therefore, the modified SHRD framework suggests that organizational awareness of both micro- and macroenvironmental contexts can increase their attention to SHRD.

However, conversely to environmental scanning being conducted only by senior managers (McCracken \& Wallace, 2000a, 2000b), the modified SHRD framework argues for the inclusion of other key organizational stakeholders (e.g., line managers, employees) to allow consideration of their perspectives, which could add value to the successful execution and outcomes of a relevant process. This could allow organizations to reach better decisions through their stakeholders' insightful contributions. Research evidence on LMs and employee involvement outlines the importance of their 'voices' being heard in organizations in all aspects of management practice, either through substantive or consultative roles (Grant, 2015; Morrison, 2014; Tangirala et al., 2013). In addition, the importance of a committed and engaged workforce (through their greater involvement) is central to enhancing organizational capabilities for successfully addressing environmental uncertainty and complexity (Fiksel, 2015). Thus, by having these stakeholders (or even more) involved, some organizations or industries are identified as being more successful in handling organizational and environmental shocks than others (Herd \& Alagaraja, 2016). These propositions are ignored in most existing 
SHRD models, whilst the modified SHRD framework addresses this gap through its respective strategic component.

Therefore, the modified SHRD framework enhances the proposition made by McCracken and Wallace (2000a: 286) for conducting "environmental scanning by senior management in HRD terms" through the inclusion of LMs and employees as well, as both could offer useful insights and recommendations while implementing relevant scanning activities. Having attained those two strategic characteristics already discussed, an equally weighted strategic component of SHRD maturity relates to the ability of HRD to shape organizational missions and goals.

\section{Shape organizational missions and goals}

Vertical or horizontal integration is vital (as suggested from most SHRD models), yet that could also imply a responsive and reactive role for HRD regarding its ability to help organizations execute their corporate strategies. Instead, SHRD must be the axis of organizational life to enable organizations to grow and change (Sthapit, 2010). This proposition could offer an indication of a more strategic-oriented HRD approach.

Especially for organizations where innovation and change are crucial, HRD is expected to play a more influential role, rather than merely being transactional and supportive (Sung \& Choi, 2013). In line with this proposition, the modified SHRD framework suggests that, in an ideal situation, HRD strategies and policies could drive and shape business goals to achieve the desired outcomes. For that to happen, multidimensional integration (vertical, horizontal, internal, and external) is required, a suggestion offered by the modified SHRD framework. Moreover, HRD would be able to influence organizational missions and goals if a strategic business partnering roles are also present, a core proposition of the modified SHRD framework. 
Concerning this specific strategic criterion, vertical integration (HRD effectiveness) can be evidenced through its ability to shape and influence business missions and goals. Therefore, it is HRD executives' responsibility to foresee any unfavorable business condition as an opportunity to demonstrate their value proposition by informing the formulation of the business strategy. Respectively, horizontal integration (HRD efficiency) suggests that HRD forms a strategic partnership with HRM to be seen as the same, and eventually to have a more significant impact on the achievement of the corporate strategies and objectives. External integration (through environmentally integrated HRD strategies, plans, and policies) could enhance the sustainability/resilience of HRD, while internal integration (HRD acceptance) could allow HRD to promote its strategic business-partnering role within the business. Each type of integration relates to a respective strategic criterion of the modified SHRD framework to collectively enhance SHRD maturity. Thus, an integrated system could allow SHRD to shape, influence, and be affected by corporate strategy subsequently. This reciprocal relationship is also expected to strengthen the strategic positioning of HRD, as well as to lead to organizational competitive advantage.

However, alignment between HRD and corporate strategy can easily be questioned as quite often it is complex and sometimes difficult to achieve (Anderson, 2009). It is complex indeed, yet the ability of HRD to shape organizational missions and goals (through multidimensional integration) could enhance its strategic outlook. Thus, future research would benefit from examining and evaluating whether such strategic alignment can be attained and whether HRD practices and policies can shape business mission and goals within challenging and dynamic contexts, such as those of an economic crisis or Brexit. Therefore, all strategic propositions of the modified SHRD framework could be applied by researchers to test their applicability and suitability for SHRD maturity under dynamic periods of change, which could result in theoretical and practical implications for the HRD field. 
For this to happen, a strategic partnership with key organizational stakeholders is also required, so that all stakeholder groups could make substantial contributions by offering their insights.

\section{Strategic partnerships with key organizational stakeholders (Senior}

\section{Management, Line Managers, Employees)}

Building strategic partnerships with key stakeholders could enable a knowledge and information exchange process, which could assist organizations in adjusting better to new business realities and enhance organizational competitiveness through better ideas generation, creativity, and innovation (Beer et al., 2015; Alagaraja, 2013a; Gibb, 2011; Anderson, 2009). Top management's support is essential, as well as the involvement of HRD professionals, when setting business strategy. However, employees' input could also prove valuable (offering insights from a different perspective), a proposition that is missing from existing SHRD models. Having attained all these strategic partnerships, it could allow HRD executives to better demonstrate their value proposition through well-informed suggestions and initiatives based on vital information provided by key stakeholders (MacKenzie et al., 2014, 2012; Shanaham et al., 2009; Phillips et al., 2007).

The modified SHRD framework suggests that in addition to building a strategic partnership with senior management, strategic alliances with line managers (LMs) and employees could also be built. McCracken and McIvor (2013) outlined a positive perception of the effectiveness of SHRD when more stakeholders are involved in decision-making. Therefore, LMs' commitment and involvement (as key organizational stakeholders) are necessary for SHRD in identifying business needs to achieve bottom-line goals (Townsend \& Loudoun, 2015; Brewster et al., 2015; Bos-Nehles et al., 2013; Alagaraja, 2013b; Wilson, 2012). The decentralization of HRD to the line is highly welcomed to allow HRD executives to concentrate 
more on strategic and long-term aspects of their work (Evans, 2015; Gooderham et al., 2015). Therefore, HRD executives should offer their ordinal support to LMs while analyzing performance problems, identifying training needs, and delivering training activities to collectively create value for the organization because of their mutual relationship/strategic partnership (Anderson, 2009). However, LMs' ability to deliver HRD initiatives is highly disputed owing to their high workload and other work-related pressures, as well as their lack of expertise in undertaking HR responsibilities (Op de Beeck et al., 2015; Bainbridge, 2015; Ryu \& Kim, 2013; Hutchinson \& Purcell, 2008).

With that in mind, the modified SHRD framework suggests that establishing a strategic partnership between LMs and the HRD executives could ensure that the former will acquire the desired competencies through relevant training (Alfes et al., 2013; Boxall \& Purcell, 2011). Having secured LMs' involvement and commitment, HRD activities could fully align at all levels (tactical, operational, and strategic) (Alagaraja, 2013b; Ford et al., 2008; Hutchinson \& Purcell, 2007). LMs could offer useful insights about HRD practices as being closest to employees, but also to benefit from their participation in relevant activities. Respectively, HRD executives could focus more on strategic and long-term aspects of their work by devolving HRD responsibilities to the line.

In addition to focusing on senior management and LMs, HRD executives also need to remain sensitive to their employees' needs, as the latter possess the physical, social, and intellectual capabilities to influence organizational attitudes, behaviors, motives, and beliefs (Cording et al., 2014; Alagaraja, 2013a; Greenwood \& Anderson, 2009; Stewart, 2008). By strategically partnering with employees, HRD executives and LMs could evaluate their needs better, and could thus illustrate their common efforts in building mutual trust between the management team and the workforce (Greenwood, 2007; Crane \& Matten, 2007). Regardless of how employees act (e.g., for their employer's interest or their own), working under the same 
objectives will favor everyone. Following relevant suggestions on the importance of “employees' line of sight” (e.g., increased organizational performance, climate and commitment - Robson \& Mavin, 2014; Dundon et al., 2004; employee satisfaction and industrial citizenship and high performance work systems - Ivars \& Martinez, 2015; Kehoe \& Wright, 2013; contribution to decision making processes and overall business success Armstrong \& Taylor, 2014; Robson \& Mavin, 2014; Bennett, 2010), the modified SHRD framework argues that establishing a strategic partnership between HRD executives and employees could only have a positive impact on the business. Such strategic collaborations could allow HRD executives to ensure that both their department and each of their stakeholders act to the benefit of all, and thus collectively contribute to organizational success (Holtbrugge et al., 2007; Chan et al., 2006), which could further result in enhancing HRD's credibility and maturity.

None of the existing models (nor that of McCracken \& Wallace) suggest a strategic partnership with employees. Therefore, the modified SHRD framework, rather than solely relying on top management support and leadership, argues for the necessity of building strategic partnerships with senior managers and LMs, as well as encouraging the buy-in of employees to get the utmost from everyone's active involvement. Besides those partnerships, HRD should also work in synergy with HRM to allow them to be seen as one, and thus to collectively enhance the strategic positioning of the HR function in organizations.

\section{Strategic partnership with HRM}

HRD can work in parallel and in synergy with HRM so that all HR initiatives can be seen as the same, eventually having a more significant impact on the achievement of the corporate strategies and objectives (McCracken \& Wallace, 2000a). Such a strategic partnership could prove helpful in enhancing HRD's strategic outlook by keeping a balance between its 
developmental and administrative services (Peterson, 2008; Wasti et al., 2008). A synergy between HRM and HRD could offer an indication of SHRD maturity following all the associated benefits. Attaining horizontal alignment of HRD and HRM could ensure the convergence of their strategic objectives to collectively contribute to business success through demonstrating their value proposition and risk reduction capacity, especially during periods of constant change, complexity, and uncertainty.

Taking that into consideration, the modified SHRD framework fully embraces the proposition offered by McCracken and Wallace (2000a; 2000b) by further suggesting that such a strategic partnership can be attained both through functional and process-based integration, both of which focus on the quality and delivery of HRD initiatives, and eventually can enhance SHRD maturity. To secure all the above, HRD executives need to undertake an extensive role, moving beyond that of the trainer that was suggested by most SHRD models.

\section{Extensive role of HRD executives}

Existing SHRD models call for HRD professionals to undertake the role of the trainer. However, for them to make a substantial strategic contribution to organizations, they also need to undertake the role of the facilitator of learning ("offer the appropriate instructional methods and techniques so to facilitate the learning experience of their trainees" - Werner \& DeSimone, 2012: 19). Further to those roles, HRD professionals should also be change agents ("advise management in the design and implementation of change strategies used in transforming organizations, along with helping individuals to change and adapt to new business realities" - ibid: 20). For HRD executives to successfully undertake all roles, leadership skills are essential to allow them to successfully drive and promote individual and organizational change (McGuire, 2014; McGuire \& Garavan, 2013; Monks et al., 2013). 
Taking all into consideration, the modified SHRD framework suggests an extensive role for HRD executives instead of solely that of a trainer. It argues for their ability to identify training and learning needs, to develop the most appropriate HRD interventions to address these needs, and to establish a learning environment that is conducive to sharing and exchanging valuable information and knowledge. By undertaking the role of 'change agent,' they can be viewed as strategic advisors offering their constant consultation on HRD matters relating to the formulation of business strategy and performance expectations. As 'consultants,' they accept a wide range of responsibilities, each of which aims at maximizing the effectiveness of their interventions: to improve communication; to enhance client relationships and support stakeholders' expectations; to improve individual and business performance; and to enhance organizational culture.

Within complex and dynamic business and economic environments, an extensive role for HRD executives is essential to ensure business survival and growth. Eventually, they need to become proactive, and thus to set rather than follow trends. The outcome of espousing such an extensive role would enable them to position themselves strategically, and their respective departments, within the board of directors of their organizations, and in return to contribute to the maturity of their HRD practices. Further to these roles, HRD executives also need to have the strategic ability to shape and influence business culture and climate through their HRD interventions.

\section{Strategic ability to shape and influence business culture and climate}

Organizational effectiveness goes hand in hand with the construction of an adaptive culture ("evolution of organizational culture due to consistent environmental change" - French et al., 2015: 390) within which organizations, and their members, can increase their flexibility and resilience to facilitate change (Griswold, 2008; Tseng \& McLean, 2008; Jones et al., 2005). 
HRD executives need to circulate the organizational cultural values to enhance cultural awareness of all organizational members, as well as to facilitate a process of cultural change when that is required (Stevens, 2013). Along with business culture, the organizational climate (“employees' shared perceptions or experiences of the policies, practices, and procedures of their workplace" - Zhang \& Liu, 2010: 190) also needs to be considered. Furthermore, within every organizational climate, the HRD climate also exists ("employees' perceptions of the availability and effectiveness of the $T \& D$ opportunities within the organization" Srimannarayana, 2007: 2), which can contribute to organizational and workforce well-being and self-renewal through a wide range of learning and developmental opportunities.

The modified SHRD framework suggests that HRD should hold the strategic ability to shape and influence organizational culture beyond simply recognizing and responding to it (existing SHRD models' propositions). Especially during business and economic uncertainty and complexity, being able to shape and influence the business culture and climate by enhancing a learning mentality within the organization could also facilitate change as well as helping both individuals and organizations respond effectively to the demanding nature of their business and economic environments (Das, 2012).

However, to be able to shape and influence business culture and climate, HRD executives need to undertake an extensive role in working towards the development of a supportive environment within which continuous learning and developmental opportunities could promote organizational competitiveness and success. The credibility and strategic outlook of HRD will also be enhanced. Evidently, a close interrelation of the proposed strategic characteristics could contribute to SHRD maturity. Thus, part of HRD executives' role is also to conduct a strategic evaluation of their HRD offerings to allow both short- and long-term results to emerge. 


\section{Emphasis on strategic HRD evaluation}

The evaluation of all HRD initiatives is a crucial component of SHRD maturity as a critical element in enhancing its credibility, as well as being a mechanism to indicate the path of transforming training into HRD and accordingly to SHRD in organizations (Rao, 2014; Walton \& Valentin, 2014). For HRD to become strategic, it should continuously demonstrate how its investments could pay off through the associated benefits for the organization, all stakeholder groups, and society (Giangreco et al., 2010).

Existing SHRD models either lack the appropriate feedback and evaluation mechanism to measure the effectiveness of HRD or focus solely on trainees' reactions to the learning experience offered. Their evaluation suggestions mainly focus on either short-term financial results or cost-effectiveness, rather than assessing long-term strategic outcomes. Thus, HRD should move beyond a cost-effective and short-oriented evaluation to a more proactive/strategic approach through which both performative and humanitarian outcomes will emerge. That would also allow HRD to enhance its strategic outlook and positioning within the organization.

In contrast, the modified SHRD framework argues for a strategic HRD evaluation to take place instead by focusing more on long-term results (e.g., behavioral and organizational change, training's return on investment, societal outcomes) as an additional indicator of SHRD maturity.

\section{SHRD maturity at a crossroads: concluding remarks}

Having discussed all the strategic components of the modified SHRD framework, the author of this paper welcomes future research to apply and test the modified SHRD framework under volatile, uncertain, complex, and ambiguous (VUCA) business environments (Li, 2016; Anderson et al., 2014). This would allow both scholars and practitioners to examine the 
strategic embeddedness of HRD (SHRD maturity) better within the constantly changing business and environmental landscapes, as well as to re-define the term. It would also help them to identify the potential problems and limitations of putting SHRD aspirations into practice under turbulent business and economic periods, and eventually to offer insightful suggestions (both theoretical and practical) on how HRD could enhance its strategic outlook and maturity in challenging times.

To further support the enhanced set of strategic components of the modified SHRD framework, the author also developed specific pointers of SHRD maturity for each one of these (table 2), which are discussed in more detail in the following section.

\section{Pointers of SHRD Maturity}

The enhanced cluster of strategic criteria that the modified SHRD framework suggests provides a way of exploring perspectives on the maturity of SHRD in organizations. The modified SHRD framework embraces McCracken and Wallace's (2000a: 432) suggestion that "all characteristics are important in their own right, but they are also interrelated. If one or more is absent or weak, then this could significantly undermine the development of SHRD, because the links with other characteristics would also be weakened". Instead, new strategic pointers (table 2) suggest a way to better assess SHRD maturity in an attempt to enhance Lee's (1996b) idea of creating a scale of SHRD maturity. The strategic pointers (critical elements for each strategic proposition) complement the strategic components of the modified SHRD framework to offer a better evaluation of SHRD maturity. Therefore, two potential states of SHRD maturity can be identified, namely the mature and the immature state. Overall, the strategic embeddedness of HRD can be evaluated through weak or strong evidence on all strategic criteria, and their strategic pointers. 


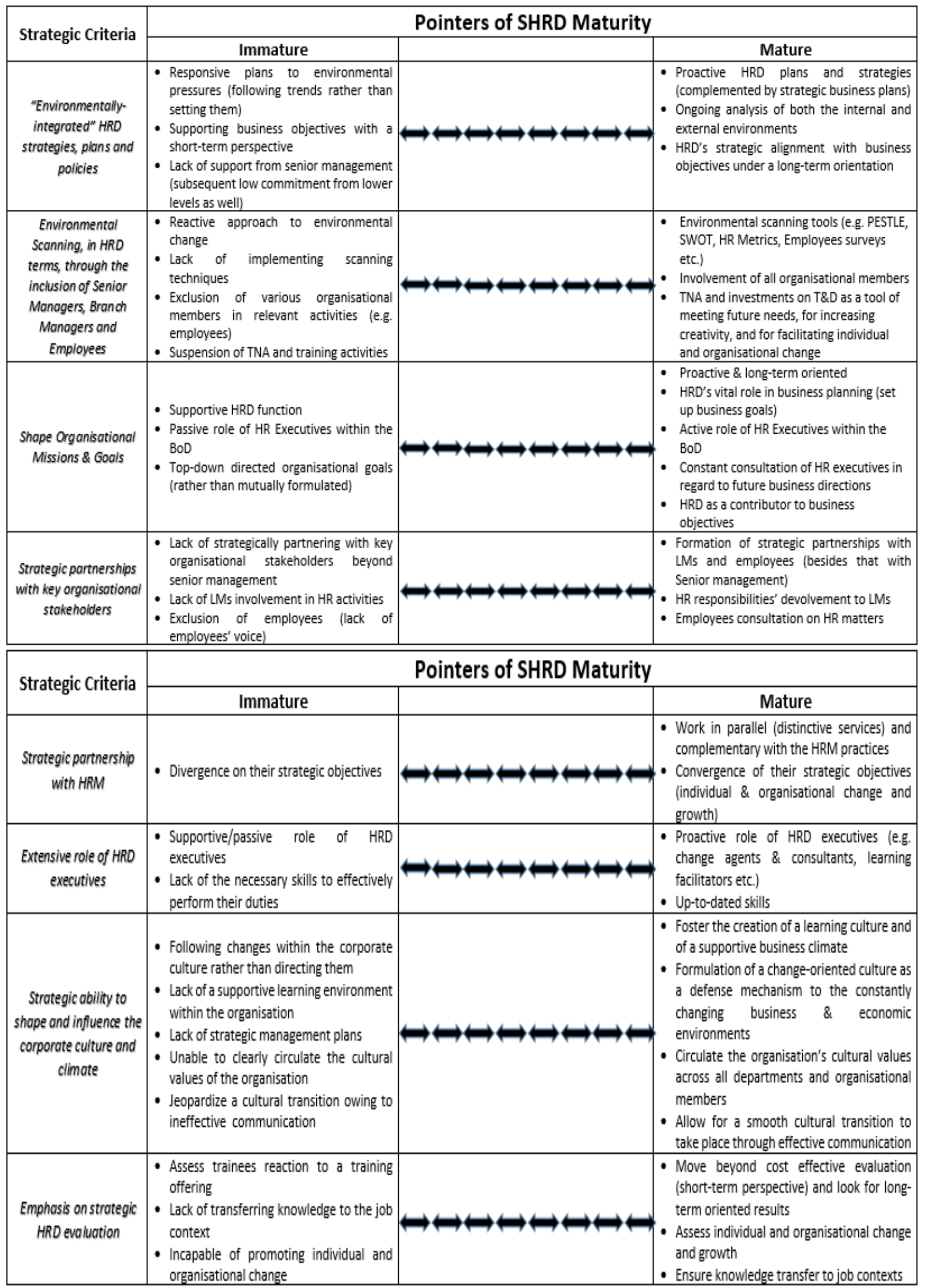

Table 2: Pointers of SHRD maturity 
Strong evidence of the right-sided pointers of the table indicates a mature organization, in HRD terms, while the opposite occurs when the left-sided pointers of the table are present. For instance, concerning ‘environmentally integrated' HRD strategies, plans, and policies, a mature state could mostly be evidenced through proactive HRD plans. Such practices could help organizations reduce operational risk, as well as increase their sensitivity against on-going change and economic uncertainty. By employing several scanning techniques (e.g., PESTLE and SWOT analysis, HR metrics, and employee surveys), organizations can constantly analyze their internal and external environments to ensure a good fit with the latest developments and changes occurring in both. Furthermore, a mature organization would also be able to change its strategies and practices at relatively short notice and low cost, while also developing and applying dynamic strategic moves to respond to emerging opportunities and developing trends. It is also expected that a strategic alignment between HRD and corporate objectives would exist under a long-term perspective (beyond their short-term orientation). For all that to happen, senior management's support is considered crucial. Having secured all these elements, a classification closer to the 'mature' state could be attained. However, when the left-sided pointers of the table are present, SHRD tends to move towards an immature state. In such a case, little-to-no scanning activities are undertaken, and HRD-business plans are mainly shortterm oriented. The support of senior managers is also lacking.

It is of equal importance to form strategic partnerships between the HRD executives and the LMs and the employees. In a mature state, HRD responsibilities are devolved to the line, while employees have a say in relevant HRD concerns. On the other hand, limited or a total lack of strategic partnering with key stakeholders could offer an indication of an immature organization for the particular strategic criterion. Finally, emphasis on strategic HRD evaluation is a prerequisite of SHRD maturity. Mature organizations are expected to focus more on long-term strategic outcomes, through which short-term results could also emerge. 
Therefore, individual and organizational change will be at the forefront, rather than solely assessing employees' reactions to training (immature). In a similar vein, mature organizations are expected to go beyond cost-effective evaluation (short-term orientation) by paying greater attention to the business results that can ensure their long-term viability. In contrast, immature organizations will mostly focus on their survival without planning for a business upturn and long-term prosperity. Respectively, mature and immature pointers relate to all strategic components of the modified SHRD framework.

Having suggested a modified cluster of strategic criteria to address the limitations of existing SHRD models, the strategic pointers enhance Lee's (1996b) scale of SHRD maturity. Future research would benefit in assessing the strategic embeddedness of HRD (SHRD maturity) by applying both to identify the change and constraints of SHRD within dynamic periods of change, as well as in times of business and economic uncertainty. Both theoretical and practical implications could be offered to elevate academic knowledge and business practice, respectively.

\section{Implications for SHRD maturity research and practice, and directions for}

\section{future research}

This integrative literature review and the development of a modified SHRD framework offer both theoretical and practical implications to HRD scholars and practitioners on how to assess the strategic embeddedness of HRD (SHRD maturity) within their research and organizational contexts, respectively. An integrative literature review on SHRD maturity was nascent; hence, the suggestions offered in this paper address a respective gap within the literature. Although much of the suggested propositions in this paper are well documented within the HRM literature, most of them are not found in the respective SHRD maturity literature. 
Research scholars could apply and test the modified SHRD framework, and its strategic pointers, to those industrial, national, and environmental contexts of their choice to examine its applicability, and thus to advance it through their suggestions. Following the evolving nature of the HRD/SHRD concepts, future research would benefit from such application and testing to enhance the notion of the SHRD maturity further, and thus to contribute to the respective literature. This integrative literature review could represent the starting point for HRD scholars to examine how organizations could strengthen the resilience of their HRD practices and whether this relates to SHRD maturity. Future research could also examine the enablers and barriers to promoting HRD resilience and maturity.

The paper further demonstrates that neither environmental contexts nor employees' voices should be ignored when assessing SHRD maturity in organizations, amongst other propositions. Therefore, to no small extent, the paper adds to the academic knowledge by highlighting the limitations of putting SHRD aspirations into practice in times of business and economic uncertainty and complexity.

Finally, the application and testing of the modified SHRD framework through a longitudinal study and by adopting a multi-constituent research perspective (e.g., examining all stakeholders' perceptions of SHRD maturity) could offer more profound insights, as well as additional suggestions on how to improve the SHRD framework and its strategic pointers for future use. All of these will eventually contribute to the SHRD literature through advancing all related terms.

The paper further offers new insights into how HRD professionals could enhance the strategic embeddedness of their HRD practices. All strategic criteria of the modified SHRD framework could inform HRD practitioners on how they could assess their HRD interventions, and whether these are moving towards a strategic direction. HRD practitioners could use them as a measurement scale/tool, along with the respective pointers of SHRD maturity. For 
instance, the multi-dimensional integration that was suggested earlier (through the environmentally integrated HRD strategies, plans, and policies strategic criterion) could allow them to remain sensitive to micro- and macro-environmental changes by designing the most appropriate HRD interventions to address the many challenges that could be associated with both. Such multi-dimensional integration could also enhance HRD professionals' strategic value proposition and risk reduction capacity (strategic outlook) by placing them ahead of their competitors as it implies a proactive approach to environmental scanning.

Besides, HRD practitioners should also welcome their employees' contributions through building strategic partnerships with them. HRD professionals should realize that all organizational stakeholders can contribute to organizational sustainability and efficiency through their inputs, a suggestion that is not shared amongst all HRD practitioners but that could make a substantial difference. The 'strategic HRD evaluation process' proposition of the modified SHRD framework can also help HRD practitioners to better demonstrate the return on investment of their HRD interventions

Overall, HRD practitioners could benefit from applying the modified SHRD framework, and all other suggestions provided by future research, to better understand how HRD reacts to external forces, such as those of a global economic crisis and Brexit, and to respectively design HRD interventions to tackle future challenges.

Certainly, HRD scholars and practitioners share similar concerns regarding the 'strategicness' of HRD in organizations. Thus, this paper can bridge the gap between theory and practice through its propositions, following Korte and Mercurio's (2017) suggestion of being pragmatic while challenging HRD assumptions, helping the HRD field to become more mature while solving organizational problems that relate with internal or external environmental challenges. 


\section{Conclusion}

This integrative literature review critically discussed the concept of SHRD maturity. A review and critique of existing SHRD models was offered by acknowledging their strengths and weaknesses. The review of the relevant literature highlighted the gaps within the respective SHRD models (e.g., models are assessed in stable business and economic environments, thus do not reflect the dynamic nature of the contemporary world; lack of employees' voices; performative or humanitarian focus). Therefore, the paper extends a large amount of knowledge around SHRD maturity by offering a better understanding through its critical stance, as well as through identifying existing limitations and offering new insights.

The author of this paper proposes a modified SHRD framework for exploring SHRD maturity. New pointers of SHRD maturity are also provided to enhance previous suggestions about the scale of SHRD maturity. The modified SHRD framework suggests an enhanced set of strategic criteria, which indicate the components of SHRD maturity. Future research could test its propositions in any industrial and national context and through a comparative study to allow a deeper understanding of SHRD maturity. Eventually, the author of this paper calls for future research to re-consider the concept of SHRD maturity under the challenging context of business and economic complexity and uncertainty (e.g., Brexit). The proposed SHRD framework could be extended in various ways, from adding new strategic components to considering various factors that could either inhibit or expedite SHRD maturity.

Future research would also benefit from a multi-stakeholder approach to assess SHRD maturity to identify how different stakeholders can understand and operationalize SHRD differently (or not) within organizations. Future research (by applying the modified SHRD framework) could offer further managerial implications to HRD executives by highlighting the aspirational versus the real role of SHRD in organizations, as well as leveraging SHRD maturity literature with further suggestions. 


\section{Declaration of conflicting interests}

The author declares no potential conflicts of interest concerning the research, authorship, and publication of this article.

\section{Funding}

The author received no financial support for the research, authorship, and publication of this article.

\section{References}

Alagaraja, M. (2013a). Mobilizing organizational alignment through strategic human resource development. Human Resource Development International, 16, 74-93. doi:10.1080/13678868.2012.740794

Alagaraja, M. (2013b). The strategic value and transaction effectiveness of HRD: A qualitative study of internal customer perspectives. European Journal of Training and Development, 37, 436-453. doi: 10.1108/03090591311327277

Alfes, K., Truss, C., Soane, E. C., Rees, C. \& Gatenby, M. (2013). The Relationship between Line Manager Behavior, Perceived HRM Practices, and Individual Performance: Examining the Mediating Role of Engagement. Human Resource Management - Special Issue: Human Resource Management and the Line, 52, 839-859. doi: 10.1002/hrm.21512 Anderson, V. (2009). Desperately seeking alignment: reflections of senior line managers and HRD executives. Human Resource Development International, 12, 263-277. doi: $10.1080 / 13678860902982009$

Anderson, V., Garavan, T. \& Sadler-Smith, E. (2014). Corporate social responsibility, sustainability, ethics, and international human resource development. Human Resource Development International, 17, 497-498. doi: 10.1080/13678868.2014.954187

Armstrong, M., \& Taylor, S. (2014). Armstrong's Handbook of Human Resource Management Practice. $13^{\text {th }}$ Edition, London: KoganPage Ltd.

Avey, J. B., Nimnicht, J. N., \& Pigeon, N. G. (2010). Two field studies examining the association between positive psychological capital and employee performance. Leadership \& Organizational Development, 31, 384-401. doi: 10.1108/01437731011056425 
Avey, J. B., Reichard, R. J., Luthans, F., \& Mhatre, K. H. (2011). Meta-analysis of the impact of positive psychological capital on employee attitudes, behaviors, and performance. Human Resource Development Quarterly, 22, 127-152. doi: 10.1002/hrdq.20070

Bainbridge, H. (2015). Devolving people management to the line: How different rationales for devolution influence people management effectiveness. Personnel Review, 44, 847-865. doi: 10.1108/PR-10-2013-0193

Bardoel, E. A., Pettit, M. T., De Cieri, H., \& McMillan, L. (2014). Employee resilience: an emerging challenge for HRM. Asia Pacific Journal of Human Resources, 52, 279-297. doi: 10.1111/1744-7941.12033

Becker, E. B., Huselid, A. M., \& Ulrich, D. (2001). The HR Scorecard; Linking People, Strategy, and Performance. Boston: Harvard Business School Press.

Beer, M., Boselie, P., \& Brewster, C. (2015). Back to the future: Implications for the field of Human Resource Management of the Multi-stakeholder Perspective Proposed 30 years ago. Human Resource Management, 54, 427-438. doi: 10.1002/hrm.21726

Bennett, T. (2010). Employee voice initiatives in the public sector: views from the workplace. International Journal of Public Sector Management, 23, 444-455. doi: $10.1108 / 09513551011058475$

Boin, A., \& Van Eaten, M. J. G. (2013). The Resilient Organization. Public Management Review, 15, 429-445. doi: 10.1080/14719037.2013.769856

Bos-Nehles, A. C., Van Riemsdijk, M. J., \& Kees Looise, J. (2013). Employee Perceptions of Line Management Performance: Applying the AMO Theory to Explain the Effectiveness of Line Managers' HRM Implementation. Human Resource Management, 52, 861-877. doi: $10.1002 / \mathrm{hrm} .21578$

Boudreau, J., \& Ramstad, P. (2004). Talent-ship, talent segmentation, and sustainability: A new HR decision science paradigm for a new strategy definition. Human Resource Management, 44, 129-136. doi: 10.1002/hrm.20054

Boxall, P. F., \& Purcell, J. (2011). Strategy and Human Resource Management. $3^{\text {rd }}$ Edition, Hampshire: Palgrave MacMillan.

Brewster, C., Brookes, M., \& Gollan, P. J. (2015). The Institutional Antecedents of the Assignment of HRM Responsibilities to Line Managers. Human Resource Management, 54, 577-597. doi: 10.1002/hrm.21632

Buller, F. P., \& McEvoy, M. G. (2012). Strategy, human resource management, and performance: Sharpening line of sight. Human Resource Management Review, 22, 43-56. doi: 10.1016/j.hrmr.2011.11.002 
Chan, A. P. C., Chan, D. W. M., Fan, L. C. N., Lam, P. T. I., \& Yeung, J. F. Y. (2006). Partnering for Construction Excellence - a reality or myth? Building and Environment, 41 , 1924-1933. doi: 10.1016/j.buildenv.2005.06.026

Chen, Y., Tang, G., Li, J., \& Paille, P. (2015). Linking Market Orientation and Environmental Performance: The Influence of Environmental Strategy, Employee's Environmental Involvement, and Environmental Product Quality. Journal of Business Ethics, 127, 479500. doi: 10.1007/s10551-014-2059-1

Cooke, F. L. (2018). Concepts, contexts, and mindsets: Putting human resource management research in perspectives. Human Resource Management Journal, 28, 1-13. doi: $10.1111 / 1748-8583.12163$

Coombs, W. T. (2014). Ongoing Crisis Communication: Planning, Managing, and Responding. $4^{\text {th }}$ Edition, Texas: Sage Publications Ltd.

Cording, M., Harrison, S. J., Hoskisson, E. R., \& Jonsen, K. (2014). Walking the Talk: A Multistakeholder Exploration of Organizational Authenticity, Employee Productivity, and PostMerger Performance. Academy Of Management Perspectives, 28, 38-56. doi: 10.5465/amp.2013.0002

Crane, A., \& Matten, D. (2007). Business ethics, a European perspective: Managing corporate citizenship and sustainability in the age of globalization. $2^{\text {nd }}$ Edition, Oxford: Oxford University Press.

Das, D. K. (2012). How did the Asian Economy Cope with the Global Financial Crisis and Recession? A Revaluation and Review. Asia Pacific Business Review, 18, 7-25. doi: $10.1080 / 13602381.2011 .601584$

David, R. F. (2016). Strategic Management: A Competitive Advantage Approach, Concepts, and Cases. $16^{\text {th }}$ Edition, Essex: Pearson Education Limited.

Dundon, T., Wilkinson, A., Marchington, M., \& Ackers, P. (2004). The meanings and purpose of employee voice. International Journal of Human Resource Management, 15, 11491170. doi: 10.1080/095851904100016773359

Evans, S. (2015). Juggling on the line: Front line managers and their management of human resources in the retail industry. Employee Relations, 37, 459-474. doi: 10.1108/ER-062014-0066

Felstead, A., Green, F., \& Jewson, N. (2012a). The Impact of the 2008-2009 Recession on Training at Work. Briefing Paper, May 2012, First Interim Report from February 2010 to September 2010, UK Commission for Employment and Skills, pp.1-34. Available at: https://orca.cf.ac.uk/67952/1/training-in-the-recession-first-interim.pdf 
Felstead, A., Green, F., \& Jewson, N. (2012b). An analysis of the impact of the 2008-2009 recession on the provision of training in the UK. Work Employment and Society, 26, 968986. doi: $10.1177 / 0950017012458016$

Fiksel, J. (2015). Resilient by Design: Creating businesses that adapt and flourish in a changing world. Washington: Island Press.

Ford, R. C., Wilderom, C. P. M., \& Caparella, J. (2008). Strategically crafting a customerfocused culture: an inductive case study. Journal of Strategy \& Management, 1, 143-167. doi: $10.1108 / 17554250810926348$

French, R., Rayner, C., Rees, G., \& Rumbles, S. (2015). Organizational Behavior. 3rd Edition, London: Wiley Publishing.

Garavan, T. N. (1991). Strategic human resource development. Journal of European Industrial Training, 15, 17-30. doi: 10.1108/EUM0000000000219

Garavan, T. N. (2007). A Strategic Perspective on Human Resource Development. Advances in Developing Human Resources, 9, 11-30. doi: 10.1177/1523422306294492

Garavan, T. N., Costine, P., \& Heraty, N. (1995). The Emergence of Strategic Human Resource Development. Journal of European Industrial Training, 19, 4-10. doi: $10.1108 / 03090599510095816$

Garavan, T. N., Shanahan, V., Carbery, R., \& Watson, S. (2016). Strategic human resource development: towards a conceptual framework to understand its contribution to dynamic capabilities. Human Resource Development International, 16, 289-306. doi: $10.1080 / 13678868.2016 .1169765$

Giangreco, A., Carugati, A., \& Sebastiano, A. (2010). Are we doing the right thing? Food for thought on training evaluation and its context. Personnel Review, 39, 162-177. doi: $10.1108 / 00483481011017390$

Gibb, S. (2011). Human Resource Development: Process, Practices, and Perspectives. $2^{\text {nd }}$ Edition, Hampshire: Palgrave Macmillan.

Gilley, W. J., \& Gilley, A. M. (2003). Strategically integrated HRD: Six transformational roles in creating results-driven programs. $2^{\text {nd }}$ Edition, Cambridge, Mass: Perseus Publishing.

Gilley, W. J., \& Maycunich, A. (2000a). Organizational Learning, Performance, and Change: An Introduction to Strategic Human Resource Development. Cambridge, Mass: Perseus Publishing.

Gilley, W. J., \& Maycunich, A. (2000b). Beyond the Learning Organization: Creating a Culture of Continuous Development through State-of-the-Art Human Resource Practices. Cambridge, Mass: Perseus Publishing. 
Gooderham, N. P., Morley, J. M., \& Stavrou, E. (2015). National and firm-level drivers of the devolution of HRM decision making to line managers. Journal of International Business Studies, 46, 715-723. doi: 10.1057/jibs.2015.5

Grant, M.B. (2015). Contemporary Strategy Analysis. th $^{\text {th }}$ Edition, Chichester: John Wiley \& Sons Ltd.

Greenwood, M. R. (2007). Stakeholder engagement: Beyond the myth of corporate responsibility. Journal of Business Ethics, 74, 315-327. Doi: 10.1007/s10551-007-9509

Greenwood, M. R., \& Anderson, E. (2009). I used to be an employee, but now I am a stakeholder: Implications of labeling employees as stakeholders. Asia Pacific Journal of Human Resources, 47, 186-200. doi: 10.1177/1038411109105441

Griswold, W. (2008). Cultures and Societies in a Changing World. $3^{\text {rd }}$ Edition, Thousand Oaks, CA: Pine Forge Press.

Gunnigle, P., Lavelle, J., \& Monaghan, S. (2013). Weathering the storm? Multinational companies and human resource management through the global financial crisis. International Journal of Manpower, 34, 214-232. doi: 10.1108/IJM-04-2013-0078

Herd, A., \& Alagaraja, M. (2016). Strategic Human Resource Development Alignment: Conceptualization from the Employee's Perspective. In C. Hughes, \& M. W. Gosney (Eds.), Bridging the Scholar-Practitioner Gap in Human Resources Development. A volume in the Advances in Human Resources Management and Organizational Development (AHRMOD) Book Series, Hersey, PA: Business Science Reference.

Holtbrugge, D., Berg, N., \& Puck, J. F. (2007). To Bribe or to Convince? Political Stakeholders and Political Activities in Germany Multinational Corporation. International Business Review, 16, 47-67. doi: 10.1016/j.ibusrev.2006.11.001

Hughes, C., \& Byrd, M. Y. (2015). Managing Human Resource Development Programs. New York: Palgrave Macmillan.

Hutchinson, S., \& Purcell, J. (2003). Bringing Policies to Life: The Vital Role of Front Line Managers in People Management. In S. Hutchinson, (Eds.). The Role of Front Line Managers in Bringing Policies to Life. (pp. 1-5). Centre for Employment Studies Research, CESR Review, April 2008, Bristol Business School.

Ivars, P. V. J., \& Martinez, C. M. J. (2015). The Effect of High-Performance Work Systems on Small and Medium Size Enterprises. Journal of Business Research, 68, 1463-1465. doi: 10.1016/j.jbusres.2015.01.034 
Jamrog, J. J., McCann, J. E. I., Lee, J. M., Morrison, C. L., Selsky, J. W., \& Vickers, M. (2006). Agility and resilience in the face of continuous change: a global study of current trends and future possibilities. New York: American Management Association.

Jiang, K., Lepak, D. P., Hu, J., \& Baer, J. C. (2012). How does human resource management influence organizational outcomes? A meta-analytic investigation of mediating mechanisms. Academy of Management Journal, 55, 1264-1294. doi: 10.5465/amj.2011.0088

Jones, A. R., Jimmienson, L. N., \& Griffiths, A. (2005). The Impact of Organizational Culture and Reshaping Capabilities on Change Implementation success: The Mediating Role of Readiness for Change. Journal of Management Studies, 42 361-386. doi: 10.1111/j.14676486.2005.00500.x

Kehoe, R. R., \& Wright, M. P. (2013). The Impact of High-Performance Human Resource Practices on Employees' Attitudes and Behaviors. Journal of Management, 39, 366-391. doi: 10.1177/0149206310365901

Korte, R., \& Mercurio, Z. A. (2017). Pragmatism and Human Resource Development: Practical Foundations for Research, Theory, and Practice. Human Resource Development Review, 16, 60-84. doi: 10.1177/1534484317691707

Lee, R. (1996a). What Makes Training Pay? London: Institute of Personnel and Development.

Lee, R. (1996b). The pay forward view of training. People Management, 2, 30.

Li, J. (2016). Technology advancement and the future of HRD research. Human Resource Development International, 19, 189-191. doi: 10.1080/13678868.2016.1181846

Lyons, R. (2016). Strategic Human Resource Development Impact on Organizational Performance: Does SHRD matter? A PhD thesis submitted to North Dakota State University of Agriculture and Applied Science. Available at: https://library.ndsu.edu/ir/bitstream/handle/10365/28020/Strategic\%20Human\%20Resou rce\%20Development $\% 20$ Impact $\% 20$ on $\% 20$ Organizational\%20Performance $\% 20$ Does $\% 2$ OSHRD\%20Matter.pdf?sequence $=1$

MacKenzie, C., Garavan, T. N., \& Carbery, R. (2014). The Global Financial and Economic Crisis: Did HRD Play a Role? Advances in Developing Human Resources, 16, 34-50. doi: $10.1177 / 1523422313508925$

MacKenzie, C. A., Garavan, T. N., \& Carbery, R. (2012). Through the looking glass: Challenges for human resource development (HRD) post the global financial crisis Business as usual? Human Resource Development International, 15, 353-364. doi: $10.1080 / 13678868.2012 .669236$ 
Marchington, M. (2015). Human resource management (HRM): Too busy looking up to see where it is going longer term? Human Resource Management Review, 25, 176-187. doi: 10.1016/j.hrmr.2015.01.007

McCracken, M., \& McIvor, R. (2013). Transforming the HR function through outsourced shared services: insights from the public sector. The International Journal of Human Resource Management, 24, 1685-1707. doi: 10.1080/09585192.2012.725070

McCracken, M., \& Wallace, M. (2000a). Towards a Redefinition of Strategic HRD. Journal of European Industrial Training, 24, 281-290. doi: 10.1108/03090590010372056

McCracken, M., \& Wallace, M. (2000b). Exploring Strategic Maturity in HRD-Rhetoric, Aspiration or Reality? Journal of European Industrial Training, 24, 425-467. doi: 10.1108/03090590010354344

McGuire, D. (2014). Human Resource Development. $2^{\text {nd }}$ Edition, London: Sage Publications Ltd.

McGuire, D., \& Garavan, T. N. (2013). Reclaiming the "D" in HRD. Paper Presented at UFHRD Conference: "HRD in Turbulent Seas - Continued Global Economic Uncertainty: Challenges and Opportunities", Brighton, UK: 5th-7th June 2013. Available at: http://www.ufhrd.co.uk/wordpress/wp-content/uploads/2013/09/McGuire-Garavan-fullpaper.pdf

Mitsakis, F.V. (2017). Employees' perspectives on strategic human resource development before and after the global financial crisis: evidence from the Greek banking sector. International Journal of Training and Development, 21, 285-303. doi: 10.1111/ijtd.12112 Mitsakis, F.V., \& Aravopoulou, E. (2016). The impact of the economic crisis upon human resource development (HRD): evidence from two Greek banks. International Journal of Human Resource Development: Practice, Policy \& Research, 1, 67-82. doi: 10.22324/ijhrdppr.1.117

Monks, K., Kelly, G., Conway, E., Flood, P., Truss, K., \& Hannon, E. (2013). Understanding how HR systems work: the role of HR philosophy and HR processes. Human Resource Management Journal, 23, 379-395. doi: 10.1111/j.1748-8583.2012.00207.x

Morrison, W. E. (2014). Employee Voice and Silence. Annual Review of Organizational Psychology and Organizational Behavior, 1, 173-197. doi: 10.1146/annurev-orgpsych031413-091328

O’Donovan, D., \& Rimland-Flower, N. (2013). The Strategic Plan is dead: Long Live Strategy. Stanford Social Innovation Review (SSIR), Available at http://www.ssireview.org/blog/entry/the_strategic_plan_is_dead._long_live_strategy 
Op de Beeck, S., Wynen, J., \& Hondeghem, A. (2015). HRM Implementation by line managers: explaining the discrepancy in HR-line perceptions of HR devolution. The International Journal of Human Resource Management, 27, 1901-1919. doi: 10.1080/09585192.2015.1088562

Paille, P., Chen, Y., Boiral, O., \& Jin, J. (2014). The Impact of Human Resource Management on Environmental Performance: An Employee-Level Study. Journal of Business Ethics, 121, 451-466. doi: 10.1007/s10551-013-1732-0

Peterson, L. S. (2008). Creating and Sustaining a Strategic Partnership: A Model of Human Resource Development. Journal of Leadership Studies, 2, 83-97. doi: 10.1002/jls.20063

Pfeffer, J. (1998). The real keys to high performance. Leader to Leader, 1998, 23-27. doi: 10.1002/lt1.40619980809

Phillips, P. P., Phillips, J. J., Stone, R. D., \& Burkett, H. (2007). The ROI Fieldbook: Strategies for Implementing ROI in HR and Training. Oxford: Elsevier.

Rao, T. V. (2014). HRD Audit: Evaluating the Human Resource Function for Business Improvement. $2^{\text {nd }}$ edition, New Delhi: Sage Publishing Ltd.

Robinson, D. G., \& Robinson, J. C. (2005). Strategic Business Partner. San Francisco: BerrettKoehler.

Robson, F., \& Mavin, S. (2014). Evaluating training and development in UK universities: staff perceptions. European Journal of Training and Development, 38, 553-569. doi: 10.1108/EJTD-04-2013-0039

Ryu, S., \& Kim, S. (2013). First-Line Managers' HR Involvement and HR Effectiveness: The Case of South Korea. Human Resource Management, 52, 947-966. doi: 10.1002/hrm.21576

Shanahan, V., Garavan, T. N., \& MacKenzie, C. (2009). The Operation of the Strategic Business Partner Model within a Services Organization. Conference Paper. International Conference on Human Resource Development Research and Practice across Europe. Available at: http://www.ufhrd.co.uk/wordpress/wp-content/uploads/2009/07/5-26refereed-paper.pdf

Srimannarayana, M. (2007). Human Resource Development Climate in Dubai Organization. Indian Journal of Industrial Relations, 43, 1-12. https://www.jstor.org/stable/27768111

Stevens, M. (2013). The Importance of intercultural skills: Does your organization value them more than professional qualifications? Available at: http://www.peoplemanagement.co.uk/pm/articles/2013/03/the-importance-ofintercultural- 
skills.htm?utm_medium=email\&utm_source=cipd\&utm_campaign=pmdaily\&utm_conte nt=070313_news_1

Stewart, A. (2008). Stewart's guide to employment law. Annandale, NSW: The Federation Press.

Sthapit, A. (2010). Integrating HRD with Organization Strategy as a Precursor to Strategic Management: A Review. Administration and Management Review, 22, 1-27. https://www.nepjol.info/index.php/AMR/article/view/5560/4578

Sung, Y. S., \& Choi, N. J. (2013). Do Organizations spend wisely on employees? Effects of training and development investments on learning and innovation in organizations. Journal of Organizational Behavior, 35, 393-412. doi: 10.1002/job.1897

Tangirala, S., Kamdar, D., Venkataramani, V., \& Parke, M. R. (2013). Doing right versus getting ahead: The effects of duty and achievement orientations on employees' voice. Journal of Applied Psychology, 98, 1040-1050. doi: 10.1037/a0033855

Torraco, R. J., \& Swanson, R. A. (1995). The strategic roles of human resource development. Human Resource Planning, 18, 10-21.

Torugsa, A. N., O’Donohue, W., \& Hecker, R. (2013). Proactive CSR: An Empirical Analysis of the Role of its Economic, Social and Environmental Dimensions on the Association between Capabilities and Performance. Journal of Business Ethics, 115, 383-402. doi: $10.1007 / \mathrm{s} 10551-012-1405-4$

Townsend, K., \& Loudoun, R. (2015). The front-line manager's role in informal voice pathways. Employee Relations, 37, 475-486. doi: 10.1108/ER-06-2014-0060

Tseng, C-C., \& McLean, N. G. (2008). Strategic HRD practices as key factors in organizational learning. Journal of European Industrial Training, 32, 418-432. doi: $10.1108 / 03090590810886544$

Ulrich, D. (1998). A new mandate for human resources. Harvard Business Review, 76, 123134. Available at: https://hbr.org/1998/01/a-new-mandate-for-human-resources

Ulrich, D., \& Dulebohn, H. J. (2015). Are we there yet? What's next for HR? Human Resource Management Review, 25, 188-204. doi: 10.1016/j.hrmr.2015.01.004

Vidal-Salazar, M. D., Cordón-Pozo, E., \& Ferrón-Vilchez, V. (2012). Human resource management and developing proactive environmental strategies: The influence of environmental training and organizational learning. Human Resource Management, 51, 905-934. doi: 10.1002/hrm.21507 
Vogel, R., \& Güttel, W. H. (2013). The Dynamic Capability View in Strategic Management: A Bibliometric Review. International Journal of Management Reviews, 15, 426-446. doi: 10.1111/ijmr.12000

Walton, J., \& Valentin, C. (2014). Human Resource Development: Practices and Orthodoxies. Basingstoke: Palgrave MacMillan.

Wang, J., Hutchins, M. H., \& Garavan, T. N. (2009). Exploring the Strategic Role of Human Resource Development in Organizational Crisis Management. Human Resource Development Review, 8, 22-53. doi: 10.1177/1534484308330018

Wasti, S. A., Poell, F. R., \& Cakar, D. N. (2008). Oceans and notions apart? An analysis of the US and European human resource development literature. The International Journal of Human Resource Management, 19, 2155-2170. doi: 10.1080/09585190802479397

Werner, J. M., \& DeSimone, L. R. (2012). Human Resource Development. $6^{\text {th }}$ Edition, Mason: Cengage Learning.

Wilson, J. P. (2012). International Human Resource Development: Learning, education, and training for individuals and organizations. $3^{\text {rd }}$ Edition, London: Kogan Page.

Zhang, J., \& Liu, Y. (2010). Organizational Climate and its Effects on Organizational Variables: An Empirical Study. International Journal of Psychological Studies, 2, 189201.doi: 10.5539/ijps.v2n2p189 


\section{APPENDIX}

Appendix 1. Review of publications referring to SHRD maturity and SHRD models

\begin{tabular}{|c|c|c|}
\hline Authors \& Publication date & $\begin{array}{c}\text { Source country of } \\
\text { research }\end{array}$ & Key suggestions \\
\hline Garavan (1991) & Ireland & $\begin{array}{l}\text { The article suggested the } \\
\text { characteristics of SHRD; } \\
\text { referred to the conditions } \\
\text { necessary for its promotion; } \\
\text { their contribution to a wider } \\
\text { HRM effort within Irish } \\
\text { organisations. }\end{array}$ \\
\hline Lee (1996a) & UK & $\begin{array}{l}\text { Suggested the ways in } \\
\text { which value for money in the } \\
\text { context of training could be } \\
\text { redefined. }\end{array}$ \\
\hline Lee (1996b) & UK & $\begin{array}{l}\text { Suggested how HRD } \\
\text { specialists could prove that } \\
\text { their training interventions } \\
\text { are a worthwhile investment } \\
\text { within their organisations so } \\
\text { to stimulate greater } \\
\text { investment on T\&D and } \\
\text { respectively to enhance the } \\
\text { strategic outlook of HRD. } \\
\text { Developed a scale to } \\
\text { measure SHRD maturity. }\end{array}$ \\
\hline Pfeffer (1998) & US & $\begin{array}{l}\text { Suggested three guiding } \\
\text { principles though which } \\
\text { HRD professionals could } \\
\text { become Chief People } \\
\text { Officers in order to enhance } \\
\text { their credibility and business } \\
\text { performance respectively. }\end{array}$ \\
\hline Ulrich (1998) & US & $\begin{array}{l}\text { Offered four suggestions as } \\
\text { to how HRD professionals } \\
\text { could enhance their } \\
\text { strategic outlook and } \\
\text { credibility through delivering } \\
\text { organisational excellence. }\end{array}$ \\
\hline McCracken \& Wallace (2000a) & UK & $\begin{array}{l}\text { Redefined SHRD and } \\
\text { provided a new SHRD } \\
\text { model with its modified } \\
\text { cluster of strategic } \\
\text { characteristics to enhance } \\
\text { the work of Garavan (1991). }\end{array}$ \\
\hline
\end{tabular}


Appendix 1. (Continued)

\begin{tabular}{|c|c|c|}
\hline Authors \& Publication date & $\begin{array}{c}\text { Source country of } \\
\text { research }\end{array}$ & Key suggestions \\
\hline McCracken \& Wallace (2000b) & UK & $\begin{array}{l}\text { Offered a conceptual } \\
\text { examination of SHRD, and } \\
\text { examined SHRD maturity } \\
\text { through their modified } \\
\text { SHRD model and its } \\
\text { enhanced strategic } \\
\text { characteristics. }\end{array}$ \\
\hline Gilley \& Maycunich (2000a) & US & $\begin{array}{l}\text { Provided a framework to } \\
\text { help HRD professionals to } \\
\text { improve their credibility and } \\
\text { organisational influence. } \\
\text { Suggested the strategic } \\
\text { elements of HRD (e.g. } \\
\text { transformation, leadership, } \\
\text { principles). how these } \\
\text { should be performed } \\
\text { (domains) and what should } \\
\text { their focus. }\end{array}$ \\
\hline Gilley \& Maycunich (2000b) & US & $\begin{array}{l}\text { Enhanced previous } \\
\text { suggestion by examining } \\
\text { how the latest advances in } \\
\text { HR principles and practices } \\
\text { can be integrated to drive } \\
\text { corporate renewal and } \\
\text { growth. }\end{array}$ \\
\hline Becker et al. (2001) & us & $\begin{array}{l}\text { Introduced a measurement } \\
\text { tool to examine how } \\
\text { HR/HRD influences } \\
\text { business performance. } \\
\text { Studied } 3,000 \text { organisations } \\
\text { and proposed a seven-step } \\
\text { process to explain how each } \\
\text { element of the HR system } \\
\text { (HR Scorecard) could } \\
\text { enhance organisational } \\
\text { performance and human } \\
\text { capital's quality in order to } \\
\text { view HR as a strategic } \\
\text { business partner within } \\
\text { organisations. }\end{array}$ \\
\hline Gilley \& Gilley (2003) & US & $\begin{array}{l}\text { Suggested a six-step } \\
\text { approach to creating results- } \\
\text { driven HRD programmes } \\
\text { through strategically } \\
\text { integrated HRD practices. }\end{array}$ \\
\hline
\end{tabular}




\begin{tabular}{|c|c|c|}
\hline Authors \& Publication date & $\begin{array}{c}\text { Source country of } \\
\text { research }\end{array}$ & Key suggestions \\
\hline Boudreau \& Ramstad (2004) & us & $\begin{array}{l}\text { Developed a model (HC } \\
\text { Bridge) which outlines the } \\
\text { logical connections } \\
\text { supporting talentship and } \\
\text { sustainability. Suggested } \\
\text { that the strategicness of HR } \\
\text { relates to their model's } \\
\text { anchor points (e.g. } \\
\text { efficiency. effectiveness. } \\
\text { impact) and the presence of } \\
\text { their linking elements } \\
\text { through identifying those } \\
\text { areas in which talent } \\
\text { management could have the } \\
\text { greatest impact. }\end{array}$ \\
\hline Robinson \& Robinson (2005) & us & $\begin{array}{l}\text { Suggested the ways through } \\
\text { which HRD professionals } \\
\text { could attain a Strategic } \\
\text { Business Partner role (SBP } \\
\text { model) within their } \\
\text { organisations in order to } \\
\text { enable them to align their } \\
\text { people strategies with the } \\
\text { business goals. }\end{array}$ \\
\hline Garavan (2007) & UK & $\begin{array}{l}\text { A review paper on SHRD. } \\
\text { Proposed a contextual and } \\
\text { dynamic framework for } \\
\text { SHRD, which is multi-level } \\
\text { and focuses on the } \\
\text { interactions between } \\
\text { context, HRD processes, } \\
\text { stakeholder satisfaction, and } \\
\text { characteristics of the HRD } \\
\text { profession. }\end{array}$ \\
\hline Shanahan et al. (2009) & Ireland & $\begin{array}{l}\text { Examined and discussed } \\
\text { the Strategic Business } \\
\text { Partner Model within a call } \\
\text { centre environment. The } \\
\text { study suggested that the } \\
\text { SBP model is evolving in the } \\
\text { call centre environment with } \\
\text { some mature SHRD } \\
\text { characteristics; yet with a } \\
\text { few transactional elements } \\
\text { to blso exist. }\end{array}$ \\
\hline Hughes and Byrd (2015) & us & $\begin{array}{l}\text { Provided practical examples } \\
\text { as to how SHRD models } \\
\text { can apply and how they can } \\
\text { guide and provide decision- } \\
\text { making, leadership } \\
\text { competencies, strategic } \\
\text { talent management, career } \\
\text { planning, and change. }\end{array}$ \\
\hline
\end{tabular}


Appendix 1. (Continued)

\begin{tabular}{|c|c|c|}
\hline Authors \& Publication date & $\begin{array}{l}\text { Source country of } \\
\text { research }\end{array}$ & Key suggestions \\
\hline Garavan et al. (2016) & UK \& Ireland & $\begin{array}{l}\text { Introduced a new concept, } \\
\text { that of "dynamic SHRD } \\
\text { capabilities }{ }^{*} \text { and proposed a } \\
\text { framework consisting of } \\
\text { specific components, } \\
\text { underlying processes, } \\
\text { enabling factors and unique } \\
\text { SHRD dynamic capabilities. }\end{array}$ \\
\hline Herd and Alagaraja (2016) & US & $\begin{array}{l}\text { Provided a model of SHRD } \\
\text { alignment from the } \\
\text { employees' perspective by } \\
\text { demonstrating the } \\
\text { connections between the } \\
\text { organisational strategy, } \\
\text { SHRD, organisational } \\
\text { learning culture and the } \\
\text { perceived investment in } \\
\text { employee development. }\end{array}$ \\
\hline Lyons (2016) & US & $\begin{array}{l}\text { Applied the Baldrige } \\
\text { Framework for performance } \\
\text { excellence to illustrate that } \\
\text { organizational performance } \\
\text { is a construct comprised of } \\
\text { multiple types of } \\
\text { organizational results and } \\
\text { that SHRD positively affects } \\
\text { this construct. The authors } \\
\text { outlined that there is a } \\
\text { causal inference between } \\
\text { an increase in the use of } \\
\text { SHRD and improved } \\
\text { organizational performance. }\end{array}$ \\
\hline Mitsakis (2017) & Greece & $\begin{array}{l}\text { Employees' perceptions of } \\
\text { SHRD maturity examined } \\
\text { and suggested a major } \\
\text { setback in the development } \\
\text { of HRD compared to its pre- } \\
\text { crisis status. SHRD was } \\
\text { presented as a theoretical } \\
\text { notion rather than an } \\
\text { organisational realitv. }\end{array}$ \\
\hline
\end{tabular}

